\title{
Sequential or Simultaneous Injection of Preformed Fibrils and AAV Overexpression of Alpha-Synuclein Are Equipotent in Producing Relevant Pathology and Behavioral Deficits
}

Matilde Negrini $^{\mathrm{a}}$, Giuseppe Tomasello ${ }^{\mathrm{a}}$, Marcus Davidsson ${ }^{\mathrm{b}, \mathrm{c}}$, Alexis Fenyi ${ }^{\mathrm{d}}$, Cécile Adant $^{\mathrm{a}}$, Swantje Hauser ${ }^{\mathrm{a}}$, Elena Espa ${ }^{\mathrm{e}}$, Francesco Gubinelli ${ }^{\mathrm{a}}$, Fredric P. Manfredsson ${ }^{\mathrm{b}}$, Ronald Melki ${ }^{\mathrm{d}}$ and Andreas Heuer ${ }^{\mathrm{a}, *}$

a Behavioural Neuroscience Laboratory, Department of Experimental Medical Sciences, Lund University, Lund, Sweden

${ }^{\mathrm{b}}$ Department of Translational Neuroscience, Barrow Neurological Institute, Phoenix, AZ, USA

${ }^{\mathrm{c}}$ Molecular Neuromodulation, Department of Experimental Medical Sciences, Lund University, Lund, Sweden

${ }^{\mathrm{d}}$ Institut Francois Jacob (MIRCen), CEA and Laboratory of Neurodegenerative Diseases, CNRS,

Fontenay-aux-Roses, France

${ }^{\mathrm{e}}$ Basal Ganglia Pathophysiology Unit, Department of Experimental Medical Sciences, Lund University, Lund, Sweden

Accepted 4 February 2022

Pre-press 23 February 2022

\begin{abstract}
.
Background: Preclinical rodent models for Parkinson's disease (PD) based on viral human alpha-synuclein (h- $\alpha$ Syn) overexpression recapitulate some of the pathological hallmarks as it presents in humans, such as progressive cell loss and additional synucleinopathy in cortical and subcortical structures. Recent studies have combined viral vector-based overexpression of human wild-type $\alpha$ Syn with the sequential or simultaneous inoculation of preformed fibrils (PFFs) derived from human $\alpha$ Syn.

Objective: The goal of the study was to investigate whether sequential or combined delivery of the AAV vector and the PFFs are equipotent in inducing stable neurodegeneration and behavioral deficits.

Methods: Here we compare between four experimental paradigms (PFFs only, AAV-h- $\alpha$ Syn only, AAV-h- $\alpha$ Syn with simultaneous PFFs, and AAV-h- $\alpha$ Syn with sequential PFFs) and their respective GFP control groups.

Results: We observed reduction of TH expression and loss of neurons in the midbrain in all AAV (h- $\alpha$ Syn or GFP) injected groups, with or without additional PFFs inoculation. The overexpression of either $\mathrm{h}-\alpha \mathrm{Syn}$ or GFP alone induced motor deficits and dysfunctional dopamine release/reuptake in electrochemical recordings in the ipsilateral striatum. However, we observed a substantial formation of insoluble $h-\alpha$ Syn aggregates and inflammatory response only when $h-\alpha$ Syn and PFFs were combined. Moreover, the presence of $\mathrm{h}-\alpha$ Syn induced higher axonal pathology compared to control groups.
\end{abstract}

\footnotetext{
*Correspondence to: Andreas Heuer, Behavioural Neuroscience Laboratory, Department of Experimental Medical Sciences,
}

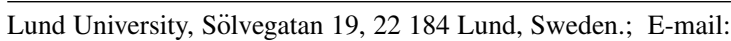
andreas.heuer@med.lu.se. 
Conclusion: Simultaneous AAV and PFFs injections are equipotent in the presented experimental setup in inducing histopathological and behavioral changes. This model provides new and interesting possibilities for characterizing PD pathology in preclinical models and means to assess future therapeutic interventions.

Keywords: AAV, alpha synuclein, behavioral deficits, dopamine, inflammation, motor deficits, Parkinson's disease, phosphorylated synuclein, preclinical rodent model, preformed fibrils

\section{INTRODUCTION}

The most common preclinical rodent models of Parkinson's disease (PD) are produced by either injecting neurotoxicants, overexpressing PDrelated genes, or by introducing mutations. Neurotoxicants such as 6-hydroxydopamine (6-OHDA) and 1-methyl-4-phenyl-1, 2, 3, 6-tetrahydropyridine (MPTP) cause a robust and rapid degeneration of the dopaminergic midbrain system, with subsequent behavioral impairments [1-6]. These approaches, however, neither replicate the alpha synuclein $(\alpha$ Syn)-linked pathology seen in PD patients $[7,8]$ nor the progressive neurodegeneration [9]. By contrast, genetic-based models, either transgenic animal lines or viral vector overexpression models, exhibit $\alpha$ Syn pathology although with variable levels of neurodegeneration and behavioral phenotypes. Viral vector-based overexpression of $h-\alpha \operatorname{Syn}$ is a promising method to trigger the desired PD-like key features. The field has gone through several generations of viral vectors [10-13] and the most commonly used are recombinant adeno-associated viral (AAV) vectors. However, there is a great heterogeneity in the results from AAV-based studies in terms of $\alpha$ Syn expression levels, neurodegeneration, and behavioral deficits. This may be due to differences in expression systems and transgene cassettes such as promoter-transgene combinations, and posttranscriptional modifying and regulatory sequences (e.g., polyA and WPRE) as well as in the choice of capsid serotype, and in the quality control of the virus itself, resulting in variable success rate [11, 14-22]. Overexpression of clinical mutations such as the A53T variant [23-25], S129D and S129A [16, 26], and A30P [24] is an alternative to exacerbate relevant pathology. Moreover, increasing dosing of AAV to elicit a greater effect may confound the experimentation as the use of control vectors (e.g., GFP) can also confer a negative effect on the integrity of nigrostriatal neurons [27-30]. Nonetheless, in a typical experimental design, neurodegeneration seen in most AAV-based expression systems has been rather moderate with usually few animals per experimental group displaying a stable behavioral phenotype.

The development of a reliable model is imperative in order to investigate the mechanisms of disease pathology as well as to test therapeutic interventions. High predictive and face-validity are needed to be able to translate approaches into clinical trials. As an example, glial cell line-derived neurotrophic factor (GDNF) showed great promise in the 6-OHDA model but failed to meet its primary endpoint in doubleblind placebo-controlled clinical trials [31-35]. A direct comparison of the effects of GDNF between the 6-OHDA model and the $\alpha$ Syn model demonstrated neuroprotection only in the 6-OHDA model [36]. The availability of a robust model that mimics the progressive cell loss, $\alpha$ Syn pathology, and stable behavioral deficits is thus currently not widely available. In the attempt of accomplishing this aim, a more recent approach combines AAV vector-based overexpression methods with injection of preformed fibrils (PFFs), which seed endogenous $\alpha$ Syn inclusions [37-41]. PFFs have been injected either 4 weeks after an AAV- $\alpha$ Syn injection [37] or simultaneously [40, 42], with the latter approach being more practical and less invasive, requiring only a single surgical intervention. Finally, the combination of ectopic human $\alpha$ Syn together with PFFs derived from the human protein allows for studies focused on studying the human synucleinopathy with minimal interference from endogenous rodent $\alpha$ Syn. In the present study we directly compare the effects of the combination of human PFFs inoculation and AAV-h- $\alpha$ Syn in the midbrain of rats, either individually, combined, or after a 4-week delay. Pathological changes were assessed by immunohistochemical analysis, electrochemical recordings, and behavioral testing. The aims of the present study were i) to establish a model that generates stable behavioral phenotypes in the majority of animals, and ii) to investigate whether there is a difference in outcomes between the sequential or simultaneous PFFs injection approach.

We report that transgene expression along the nigrostriatal pathway in all the AAV-injected groups 
A

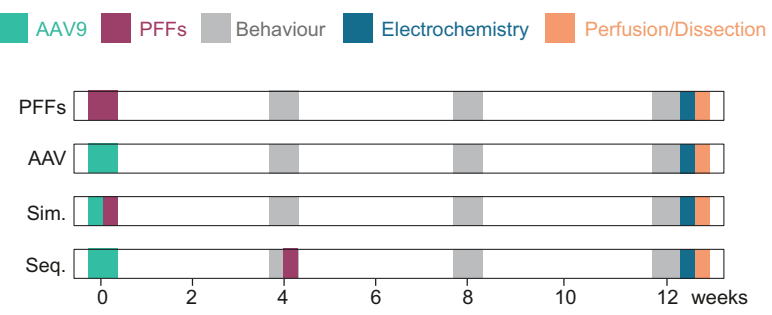

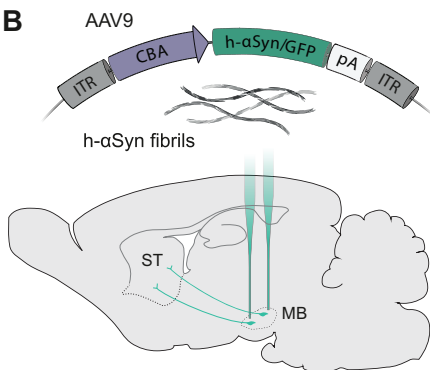

Fig. 1. Experimental layout. A) Description of the experimental groups and timepoints for behavioral test, electrochemical analysis, perfusions, and dissections. One group was injected with PFFs only (PFFs), two groups received either AAV-h- $\alpha$ Syn or AAV-GFP (AAV), two groups received AAV-h- $\alpha$ Syn or AAV-GFP and PFFs simultaneously (Sim.), and two groups received AAV-h- $\alpha$ Syn or AAV-GFP and PFFs sequentially (Seq.). B) Schematic of the pre-formed fibrils and viral genome expressing $h-\alpha$ Syn or GFP under the CBA promoter injected into the midbrain of rats. ITR, inverted terminal repeat; CBA, chicken $\beta$-actin; pA, polyadenylation site; h- $\alpha$ Syn, human alpha-synuclein; GFP, green fluorescent protein; PFFs, preformed fibrils; MB, midbrain; ST, striatum.

Table 1

Experimental groups. Schematic of the experimental groups and sample size for the analyses. Echem, electrochemistry; IHC, immunohistochemistry

\begin{tabular}{|c|c|c|c|c|c|c|c|c|}
\hline Group Name & Description & $\begin{array}{c}\text { AAV } \\
\text { injection }\end{array}$ & $\begin{array}{c}\text { PFFs } \\
\text { injection }\end{array}$ & $\mathrm{N}$ Tot & Behavior & FRET & Echem & $\overline{\mathrm{IHC}}$ \\
\hline PFFs & PFFs only & - & week 0 & 8 & 8 & 3 & 3 & 5 \\
\hline h- $\alpha$ Syn & AAV only & week 0 & - & 8 & 8 & 3 & 3 & 5 \\
\hline h- $\alpha$ Syn/PFFs & Simultaneous & week 0 & week 0 & 10 & 10 & 3 & 3 & 7 \\
\hline h- $\alpha$ Syn+PFFs & Sequential & week 0 & week 4 & 9 & 9 & 3 & 3 & 6 \\
\hline GFP & AAV only & week 0 & - & 8 & 8 & 3 & 3 & 5 \\
\hline GFP/PFFs & Simultaneous & week 0 & week 0 & 10 & 10 & 3 & 3 & 7 \\
\hline GFP+PFFs & Sequential & week 0 & week 4 & 10 & 10 & 3 & 3 & 7 \\
\hline
\end{tabular}

(both AAV-h- $\alpha$ Syn and AAV-GFP) produces downregulation of tyrosine hydroxylase $(\mathrm{TH})$ expression in the midbrain and striatum, irrespective of whether the AAV-vector was injected alone or in combination with PFFs. These animals also displayed altered dopamine release and reuptake kinetics in electrochemical recordings as well as motor impairments which did not recover over time. However, only when AAV-h- $\alpha$ Syn was combined with PFFs we observed phosphorylated $\alpha$ Syn similar to that seen in patient brains. Moreover, the combination of PFFs and AAV-h- $\alpha$ Syn triggered an enhanced inflammatory response around the area of transduction, which was not observed in the remaining experimental groups. Lastly, the presence of ectopic $h-\alpha$ Syn induced strong axonal pathology, with elevated numbers of striatal axonal swellings on the side of injection.

\section{MATERIALS AND METHODS}

\section{Animals}

All experimental procedures performed in this study were approved by the Malmö/Lund Ethics Committee on Animal Testing as well as according to Swedish national guidelines (Jordbruksverket) and the EU Directive 2010/63/EU for animal experiments. Sixty-four adult (220-250g) female Sprague-Dawley rats were purchased from Janvier Labs (France) and were housed under a 12:12 h dark:light cycle with ad libitum access to food and water in a temperature-controlled room in standard laboratory cages. A total of 64 rats were used in the current study and allocated randomly to the seven experimental groups.

\section{Experimental outline}

Naive Sprague-Dawley rats $(n=63)$ were randomly assigned into seven experimental groups receiving PFFs and AAV-vector overexpressing h$\alpha$ Syn or GFP either alone or in combination (see Fig. 1 and Table 1). In the combination groups, one group received both PFFs and AAV simultaneously (h- $\alpha$ Syn/PFFs and GFP/PFFs) and in the other group PFFs inoculation followed the AAV injection sequentially after a four-week delay ( $h-\alpha$ Syn + PFFs and GFP + PFFs). All rodents were subjected to a battery of behavioral tests at four-weeks intervals (i.e., week 4, 8, and 12 after the first injection). Twelve weeks 
after the first surgical session we performed electrochemical recordings for dopamine (DA) from three anaesthetized rats per group. After all data was collected, we either perfused the animals with PFA and harvested the brains for immunohistochemistry (5-7 rats per group) or we harvested the brains (three rats per group) for dissections of midbrain and striatum, and snap-froze the tissue for subsequent quantification of phosphorylated $\alpha$ Syn protein. A single rat was injected with the neurotoxin 6-OHDA for histological comparison.

\section{Preformed fibrils production}

Human wild type $\alpha$ Syn was expressed in E. coli BL21 DE3 CodonPlus cells (Stratagene, San Diego, CA, USA) and purified and assembled into the fibrillar polymorph "Fibrils" as described previously [43]. Briefly, the protein $(100 \mu \mathrm{M})$ was incubated in $50 \mathrm{mM}$ Tris- $\mathrm{HCl}, \mathrm{pH} 7.5,150 \mathrm{mM} \mathrm{KCl}$ at $37^{\circ} \mathrm{C}$ under continuous shaking in an Eppendorf Thermomixer set at $600 \mathrm{rpm}$ for 5 days while withdrawing aliquots $(20 \mu \mathrm{l})$ at different time intervals, mixing them to Thioflavin $\mathrm{T}(10 \mu \mathrm{M}$ final) and recording the fluorescence increase on a Cary Eclipse Fluorescence Spectrophotometer (Varian Medical Systems Inc., Palo Alto, CA, USA) using an excitation wavelength $=440 \mathrm{~nm}$, an emission wavelength $=480 \mathrm{~nm}$ and excitation and emission slits set at 2 and $5 \mathrm{~nm}$, respectively. The assembly reaction completion was also assessed by sedimentation at $100,000 \mathrm{~g}$ at $25^{\circ} \mathrm{C}$ for $30 \mathrm{~min}$ and measurement of the amount of protein remaining in the supernatant. The fibrillar nature of $\alpha$ Syn was assessed by transmission electron microscopy (TEM) after adsorption of the fibrils onto carbon-coated 200 mesh grids and negative staining with $1 \%$ uranyl acetate using a Jeol 1400 transmission electron microscope. The images were recorded with a Gatan Orius CCD camera (Gatan, Pleasanton, CA, USA). The resulting $\alpha$ Syn fibrils were fragmented by sonication for $20 \mathrm{~min}$ in $2 \mathrm{ml}$ Eppendorf tubes in a Vial Tweeter powered by an ultrasonic processor UIS250v (250 W, 2.4 kHz; Hielscher Ultrasonic, Teltow, Germany) to generate fibrillar particles with an average size $42-52 \mathrm{~nm}$ as assessed by TEM analysis. The final fibrils concentration was quantified to be $350 \mu \mathrm{M}$ e.g., $5 \mu \mathrm{g} / \mu \mathrm{L}$. Fibrils were flash frozen in liquid nitrogen ( $6 \mu \mathrm{l}$ aliquots) and stored at $-80^{\circ} \mathrm{C}$ until use. To defrost the samples, tubes were placed in a water bath at $37^{\circ} \mathrm{C}$ and incubated for $3 \mathrm{~min}$. After incubation, samples were stored at room temperature and utilized within the same day.

\section{AAV production}

AAV was produced as previously described [44]. HEK293T cells were triple transfected with either CBA-human $\alpha$ Syn or CBA-GFP, pAAV2/ 9 and the helper plasmid pXX6. AAVs were purified by iodixanol ultracentrifugation gradient and concentrated using centrifugation columns (Orbital Biosciences). Titration was performed using digital droplet PCR (ddPCR) with primers specific for the ITRs (forward primer 5'-CGGCCTCAGTGAGC GA-3' and reverse primer 5'-GGAACCCCTAGTG ATGGAGTT-3'). The AAVs batches were diluted to a working titer of $6 \times 10^{12} \mathrm{gc} / \mathrm{mL}$ using modified PBS.

\section{Stereotaxic surgery}

Intracerebral injections were performed under general anesthesia using Isoflurane (Attane vet $1000 \mathrm{mg} / \mathrm{g}$, VM Pharma AB) in a $2 \%$ air mixture. All working solutions containing viral vector and/or PFFs were prepared so that the final concentrations of viral vector and PFFs were $6 \times 10^{12} \mathrm{gc} / \mathrm{mL}$ and $2.5 \mu \mathrm{g} / \mu \mathrm{L}$, respectively. Animals were head-fixed in a stereotaxic frame with the incisor bar adjusted to the flathead position $(-4.5 \mathrm{~mm}$ below the interaural line). Each solution was infused unilaterally into the midbrain using a pulled glass capillary attached to a $10 \mu \mathrm{L}$ Hamilton syringe. The following coordinates (from Bregma, in $\mathrm{mm}$ ) and volumes were utilized: $2 \mu \mathrm{L}$ at $\mathrm{AP}=-5.3, \mathrm{ML}=-0.8, \mathrm{DV}=-7.5$ and $2 \mathrm{uL}$ at $\mathrm{AP}=-5.6, \mathrm{ML}=-2.3, \mathrm{DV}=-7.5$ with an infusion rate of $0.5 \mu \mathrm{L} / \mathrm{min}$. After injection, the syringe was left in place for additional $3 \mathrm{~min}$ and thereafter slowly retracted. 6-OHDA was injected as described previously [45]. In brief, $5.41 \mu \mathrm{g} / \mu \mathrm{L}$ 6-OHDA (calculated from free-base 6-OHDA-HBr salt, Sigma) was dissolved in $0.2 \mathrm{mg} / \mathrm{ml}$ ascorbic acid in $0.9 \%$ sterile saline and a volume of $3 \mu \mathrm{L}$ was injected at the following coordinates $\mathrm{AP}=-4.0, \mathrm{ML}=-1.3, \mathrm{DV}=-7.0$. The injection speed was set to $1 \mu \mathrm{L} / \mathrm{min}$ and the needle was left in place for an additional 3 min to allow for diffusion of the toxin.

\section{Behavioral analysis}

All behavioral assessment was performed at 4, 8, and 12 weeks after lesion by the same researcher, blind to the rats' treatment group.

\section{Drug-induced rotations}

Rats were injected i.p. with $2.5 \mathrm{mg} / \mathrm{kg} d$-amphetamine (Apotheksbolaget) and placed in automated 
rotameter bowels modelled after the design of Ungerstedt $[6,46]$. All full ipsilateral and contralateral rotations, with respect to the side of injection, were quantified over $90 \mathrm{~min}$. The data are presented as average rotations per minute.

\section{Stepping test}

Forelimb akinesia was assessed by quantifying forelimb adjusting steps as previously described [47, 48]. In brief, rats were constrained by the experimenter so that only one forelimb was freely movable. The animal was moved sideways over $90 \mathrm{~cm}$ at a constant speed. The number of both backward and forward adjusting steps was counted three consecutive times for each paw. Out of the three trials, the best two trials, in terms of number of steps performed, were averaged, and adjusting steps data was presented as percentage bias.

\section{Cylinder test}

Forelimb asymmetry in exploratory behavior was assessed by placing the animals in a glass cylinder and recording with a digital video camera for a total of $5 \mathrm{~min}$ [49]. The number of right and left forepaw weightbearing touches for a total of 20 touches was counted post-hoc by a blinded researcher and the score was expressed as percentage bias. Two GFP/PFFs rats were removed from the final analysis of the Cylinder test at week 4, two h- $\alpha$ Syn rats, three GFP rats, one GFP/PFFs rat and one GFP + PFFs rat at week 8, three GFP rats, two GFP/PFFs rats and two GFP + PFFs rats at week 12 due to a failure to complete at least 15 touches.

\section{Electrochemistry}

In vivo electrochemical chronoamperometric recordings were performed as previously described $[50,51]$ using Nafion $®$-coated carbon fiber electrodes (Ø $30 \mu \mathrm{m}, \mathrm{L} 150 \mu \mathrm{m}$, Quanteon) coupled to FAST-16mkII hardware (Quanteon). DA release was induced by local injection of $220-240 \mathrm{~nL}$ $\mathrm{KCl}(120 \mathrm{mM}, \mathrm{pH}=7.4)$ through a glass capillary connected to a picospritzer (Aldax) micropressure system (15-20 PSI for 0.1-0.5 s). The glass capillary was mounted $\sim 50-100 \mu \mathrm{m}$ from the electrode tip. Before the recording, each electrode was calibrated in 0.1 M PBS. Only electrodes with a linear response rate to three $2 \mu \mathrm{M}$ additions of DA $\left(\mathrm{r}^{2}<0.995\right)$ were selected. Moreover, only electrodes that displayed a selectivity of 1:100 over ascorbic acid and a limit of detection smaller than 0.01 MM DA were used [52].
During in vivo recordings, an $\mathrm{Ag} / \mathrm{AgCl}$ reference electrode was used which was previously prepared by electroplating an $\mathrm{Ag}$ wire in $\mathrm{NaCl}$-saturated $1 \mathrm{M}$ $\mathrm{HCl}$ solution. High-speed $(4 \mathrm{~Hz})$ chronoamperometric recordings were performed by applying a square wave potential $(+0.55 \mathrm{~V} ; 0 \mathrm{~V}$ resting $)$ and the resulting oxidation and reduction currents were analyzed using the F.A.S.T. analysis software. For each recording, the electrode-micropipette assembly was left in the recording site for at least $30 \mathrm{~min}$ to stabilize before 4 recordings were made at $10 \mathrm{~min}$ intervals.

\section{Perfusion}

Animals were given a terminal anesthetic dose of Sodium Pentobarbital i.p. and transcardially perfused by infusing approximately $150 \mathrm{~mL}$ of $0.9 \%$ saline solution at RT, followed by $250 \mathrm{~mL}$ ice-cold $4 \%$ paraformaldehyde (PFA, $\mathrm{pH}=7.4$ ) in $0.1 \mathrm{M}$ phosphate buffer. After perfusion, the brain was removed from the skull and stored in 4\% PFA solution for additional $24 \mathrm{~h}$ before being transferred into a $25 \%$ sucrose and $0.01 \% \mathrm{NaN} 3$ solution where they were kept until they sunk.

\section{Immunohistochemistry}

Brains were sectioned on a freezing sledge microtome (Leica) at a section thickness of $40 \mu \mathrm{m}$ and collected in a 1:12 series. Sections were stored in antifreeze solution at $-20^{\circ} \mathrm{C}$ until further use. The protocol for immunohistochemistry has been described elsewhere [53] and a list of the primary and secondary antibodies used can be found in Table 1. Briefly, tissue sections were washed (3x) in potassium phosphate buffered saline (KPBS, $\mathrm{pH}=7.4$ ) and then incubated for $15 \mathrm{~min}$ in $3 \% \mathrm{H}_{2} \mathrm{O}_{2}, 10 \%$ methanol in PBS to quench endogenous peroxidase activity. After (3x) PBS washes, sections were incubated for $1 \mathrm{~h}$ in blocking solution consisting of 5\% serum in KPBS and $0.25 \%$ Triton $\mathrm{X}-100$ (TPBS, $\mathrm{pH}=7.4$ ). The sections were then incubated in primary antibody in $5 \%$ serum overnight at room temperature. On the second day, sections were rinsed with (2x) KPBS and subsequently incubated in $5 \%$ serum for $1 \mathrm{~h}$ before being incubated for $1 \mathrm{~h}$ in secondary antibody solution in $5 \%$ serum. The secondary antibody was removed by $(3 \mathrm{x}) \mathrm{KPBS}$ washes and sections were incubated in avidin-biotin-peroxidase complex (ABC, Vectorlabs) in KPBS for $1 \mathrm{~h}$. After an additional (3x) KPBS washes sections were incubated for 2-10 $\mathrm{min}$ in a peroxidase (HRP) detection system (Vector ${ }^{\circledR}$ DAB, 
Table 2

Antibodies and dyes used in the current study for immunohistochemical analysis

\begin{tabular}{lccc}
\hline Antibody & Species & Cat. no & Concentration \\
\hline Human $\alpha$ Synuclein 211 & Mouse & SC-12767 & $1: 1000$ \\
GFP & Chicken & A10262 & $1: 10000$ \\
$\alpha$ Synuclein, p-S129 & Rabbit & ab51253 & $1: 100000$ \\
$\alpha$ Synuclein 81A (p-S129) & Mouse & AB184674 & $1: 10000$ \\
CD11b (Ox42) & Mouse & MCA275G & $1: 500$ \\
TH & Sheep & ab113 & $1: 750-1: 1000$ \\
TH & Mouse & MAB318 & $1: 1000$ \\
VMAT2 & Rabbit & 20042 & $1: 10000$ \\
Ubiquitin & Rabbit & AB7780 & $1: 200$ \\
ThioflavinS & - & T1892 & $1: 100$ \\
DAPI & - & D9542 & $1: 2000$ \\
Anti-rabbit Biotinylated & Goat & BA6000 & $1: 200$ \\
Anti-mouse Biotinylated & Horse & BA2001 & $1: 200$ \\
Anti-chicken Biotinylated & Goat & BA9010 & $1: 200$ \\
Anti-sheep Alexa 488 & Donkey & A11015 & $1: 500$ \\
Anti-chicken Alexa 488 & Chicken & A11039 & $1: 500$ \\
Anti-rabbit Alexa 488 & Goat & A11008 & $1: 500$ \\
Anti-rabbit Alexa 568 & Goat & A11011 & $1: 500$ \\
Anti-mouse Alexa 568 & Goat & A11004 & $1: 500$ \\
Anti-mouse Alexa 647 & Donkey & A31571 & $1: 500$ \\
Anti-rabbit Alexa 647 & Goat & A21245 & $1: 500$ \\
\hline
\end{tabular}

Vector Laboratories). The sections were mounted on gelatine-coated glass slides, dehydrated in an ascending series of ethanol $(70 \%, 95 \%, 99.5 \%, 99.5 \%)$ for 2 min each, followed by (2x) 2 min incubations in xylene to remove lipids and cover-slipped using DPX mounting medium. For fluorescence immunohistochemistry, the quenching step, the $\mathrm{ABC}$ incubation, and the DAB reaction were skipped; instead, sections were incubated for $1 \mathrm{~h}$ in fluorophore-conjugated secondary antibody, washed $(3 \mathrm{x})$ in KPBS, mounted onto gelatine-coated glass slides and cover-slipped as soon as dry using PVA/DABCO solution. When DAPI was needed, sections were incubated for $5 \mathrm{~min}$ at RT before the last washing step. Thioflavin S coloration was executed as described elsewhere [54].

\section{Proteinase K treatment}

Coronal sections were mounted on permafrostglass slides and were incubated in proteinase $\mathrm{K}$ solution $(25 \mu \mathrm{g} / \mathrm{mL}$; QIAGEN) for one hour at room temperature before proceeding with the immunostaining for pSer129 as described above.

\section{Dissections}

Three rats per group were sacrificed by decapitation at 13 weeks post-injection. Brains were extracted, rinsed in $0.9 \%$ saline solution, and coronally sectioned using a rat brain matrix on ice. The striatum and midbrain from each hemisphere were dissected using sterile razor blades. Tissue samples were snap-frozen in isopentane on dry ice and stored in $1.5 \mathrm{~mL}$ Eppendorf tubes at $-80^{\circ} \mathrm{C}$ until further processing.

\section{Brain tissue homogenization}

Frozen tissues were weighed in $2 \mathrm{ml}$ Eppendorf tubes. The samples were diluted ten times in $150 \mathrm{mM}$ $\mathrm{KCl}, 50 \mathrm{mM}$ Tris- $\mathrm{HCl} \mathrm{pH} 7.5$ to obtain a homogenate at $10 \%$ (weight:volume). The homogenization was performed by sonication using the SFX 150 Cell Disruptor sonicator with a $3.17 \mathrm{~mm}$ microtip probe (Branson) for $15 \mathrm{~s}$, with $1 \mathrm{~s}$ pulses followed by $1 \mathrm{~s}$ pauses in a biosafety level 3 environment (BSL-3). The homogenates were aliquoted and immediately frozen in liquid nitrogen before storage at $-80^{\circ} \mathrm{C}$. All contaminated surfaces were cleaned with SDS (1\%) [55].

\section{Protein quantification}

The quantification by TR-FRET of phosphorylated $\alpha$ Syn at Ser-129 or aggregated $\alpha$ Syn was performed using a fluorescence resonance energy transfer (FRET) assay (Cisbio, France, cat \#6FSYNPEG and \# 6FASYPEG respectively). Briefly, the brain homogenates were diluted to $5 \%(\mathrm{~W}: \mathrm{V})$ in lysis buffer provided in the HTRF kit. For phosphorylated $\alpha$ Syn assay, $16 \mu \mathrm{L}$ of each diluted brain homogenates were loaded into a 96 well plate and mixed with $4 \mu \mathrm{L}$ of the FRET donor and acceptor antibodies in the kit. For aggregated $\alpha$ Syn assay, $10 \mu \mathrm{L}$ of each diluted brain homogenates were loaded into a 96 well plate and mixed with $10 \mu \mathrm{L}$ of the FRET donor and acceptor antibodies in the kit. The plates were sealed with a film (CmlAB, Denmark, cat \#13076-9P-500) and incubated for $20 \mathrm{~h}$ at $20^{\circ} \mathrm{C}$ without shaking in a Thermomixer comfort (Eppendorf, Montesson, France). Time-resolved FRET was measured after incubation upon excitation at $337 \mathrm{~nm}$ using a plate reader (CLARIOstar, BMG Labtech, Germany) as described [56]. The HTRF signal was recorded at two different wavelengths $(665 \mathrm{~nm}$ and $620 \mathrm{~nm})$. The amount of aggregated $\alpha$ Syn was derived from the $665 / 620 \mathrm{~nm}$ fluorescence ratio and multiplied by 10000 .

\section{Densitometry}

High resolution scans were taken with an Epson flatbed scanner at $600 \mathrm{DPI}$. The level of staining intensity was measured from 4 striatal sections 
$(\mathrm{AP}+1.6,+0.7,-0.26$, and $-0.6 \mathrm{~mm})$ for $\alpha \mathrm{Syn} 211$ DAB, GFP-DAB and TH-DAB and one midbrain section (AP: $-5.6 \mathrm{~mm}$ ) for OX42-DAB, using ImageJ software (NIH, Version 1.8.0). Before measurement, each image was transformed into grayscale 8-bit and calibrated using a step-tablet from Epson with known OD values using the Rodbard function (https://ima gej.nih.gov/ij/docs/examples/calibration/). Correction for non-specific background was done by subtracting values obtained from the corpus callosum to the measured values. The regions of interest were outlined, and the grey-pixel intensity value average was measured. The data are expressed as optical density values of contralateral vs ipsilateral striatum or midbrain.

\section{Stereology}

Quantification of $\mathrm{TH}^{+}$cells in the substantia nigra pars compacta $(\mathrm{SNpc})$ was performed according to the optical fractionator principle using ImageJ Software (NIH, Version 1.8.0) [57]. In brief, z-stack images of every sixth series (section sampling fraction, $s s f=1 / 6$ ) of the $\mathrm{SNpc}$ region were acquired at 20X magnification using a Leica DMi8 microscope, which yielded to $8-10$ sections per animal. The average mounted section thickness $(\mathrm{t})$ was $20 \pm 2.6 \mu \mathrm{m}$ and the heigh of optical dissector (h) used was $12 \mu \mathrm{m}$ ( $3 \mu \mathrm{m}$ guard zones). Grid area was set at 170x170 $\mu \mathrm{m}$ and the counting frame size at $55 \times 55 \mu \mathrm{m}$. A maximal coefficient of error (CE) of 0.11 for the intact side was accepted and animals with higher $C E$ values were excluded from the analysis.

\section{Axonal swellings quantification}

Quantification of striatal axonal swellings was performed following $\alpha$ Syn 211 , GFP and TH DAB-IHC. Three high-resolution $63 \mathrm{X}$ z-stacks were taken from central, dorso-medial, and dorso-lateral regions of the striatum as previously described [19]. Each z-stack had a $\mathrm{z}$-step size of $1 \mu \mathrm{m}$ for a total of $30 \mathrm{z}$-steps. The ImageJ 3D object count tool was used to identify the swellings and calculate their total number, as well as their volume, by setting an exclusion threshold for particles $<4 \mu \mathrm{m}^{3}$ and circularity between $0.5-1.0$. The average number and volume size of swellings was calculated based on the total swelling number from all the three pictures from one animal and for Fig. 7M and $7 \mathrm{O}$ and Supplementary Figure 5G and $5 \mathrm{I}$ were divided in small $\left(4-10 \mu \mathrm{m}^{3}\right)$, medium $\left(10-20 \mu \mathrm{m}^{3}\right)$ and large $\left(>20 \mu \mathrm{m}^{3}\right)$.

\section{Statistics}

All data were analyzed using the statistical software GraphPad Prism (V 8.4.3) using an alpha of 0.05 as threshold for determining statistical significance. For group and group by side analysis we performed analysis of variance with the factors Group and Side as dependent variables. For time-course analysis we performed repeated measures ANOVAs with the factors Week and Group. Post hoc testing used Sidak's correction were applied to avoid Type 1 errors/inflating alpha due to multiple comparison testing.

\section{RESULTS}

In the current study we injected PFFs and/or $\alpha$ Syn overexpressing AAV either individually or in combination, simultaneous or sequentially after a 4-week delay, to induce a pathologically relevant level of neuronal cell loss in the midbrain of rats.

\section{Injection of $A A V-h-\alpha$ Syn leads to strong overexpression of $\alpha$ Syn along the nigrostriatal pathway}

We first assessed the expression of $h-\alpha$ Syn throughout the nigrostriatal pathway at 12 weeks following vector delivery. The groups injected with AAV-h- $\alpha$ Syn displayed strong $\alpha$ Syn immunoreactivity on the injected side of the midbrain with evident spread along dopaminergic nigrostriatal projections (Fig. 2A-D) with some diffusion into the contralateral hemisphere in the midbrain. The comparison of the staining intensity between the left and right striatum (Fig. 2E) for the four treatment groups showed that there was a significant difference in human synuclein immunoreactivity between the groups and the side of the brain analyzed (Groups*Side, $\mathrm{F}_{3,18}=6.88, p<0.01$ ). All groups injected with AAV-h- $\alpha$ Syn displayed a similar degree of $\alpha$ Syn immunoreactivity which was absent in the group that received PFFs only (Sidak, all $p<0.0001)$. Triple immunofluorescent immunoreactivity for the enzyme tyrosine-hydroxylase (TH), the Vesicular Monoamine Transporter 2 (VMAT2), and $\alpha$ Syn 211 (human $\alpha$ Syn) confirmed that the midbrain dopaminergic neurons of the PFFs-inoculated group did not express $\mathrm{h}-\alpha$ Syn (Fig. $2 \mathrm{~F}-\mathrm{F}_{\text {iii }}$ ), whereas all groups receiving the AAV-vector expressed $h-\alpha S y n$ throughout most of the midbrain dopamine neurons (Fig. 2G-I $\mathrm{I}_{\mathrm{iii}}$ ). The lack of staining in the PFFs treated 


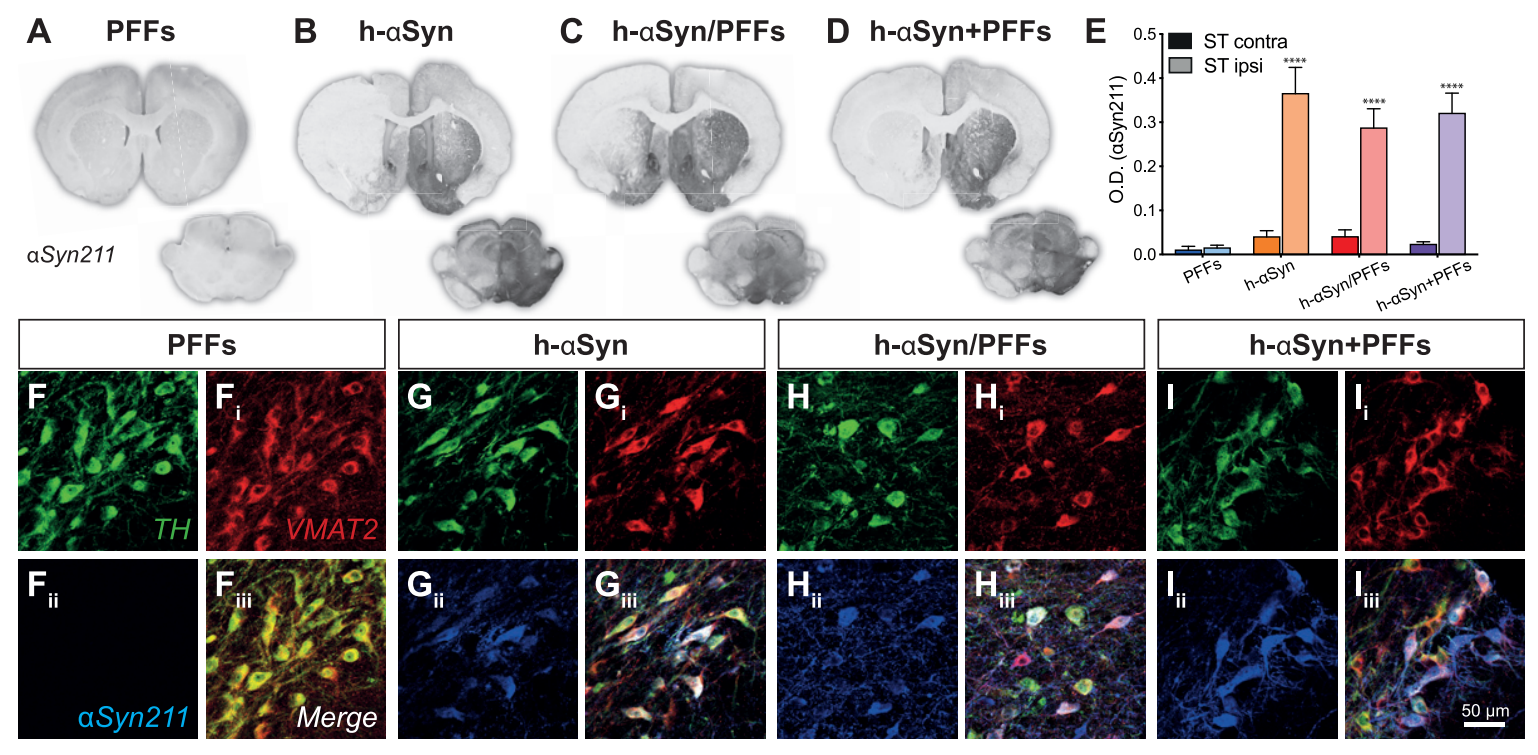

Fig. 2. AAV-vector overexpression. A-D) Representative midbrain and striatal sections for each group stained for human $\alpha$ Syn ( $\alpha$ Syn211). E) Densitometric analysis comparing human $\alpha$ Syn211 staining intensity between contralateral and ipsilateral right striatum. F- $\mathrm{I}_{\mathrm{iii}}$ ) Triple immunofluorescence demonstrating colocalization between TH, VMAT2, and $\alpha$ Syn 211 antibodies in SNpc. PFFs, preformed fibrils; $h-\alpha$ Syn, human alpha-synuclein; contra, contralateral; ipsi, ipsilateral; O.D., optical density. Data are expressed as mean \pm SEM. (**** $p<0.0001)$.

group is not surprising as the 211 antibody is directed against the C-terminal end of the human protein, which is known to be cleaved off rapidly [58]. Similar results were observed for the GFP expression in the control groups (Supplementary Figure 1A-C) where we observed a significant difference in GFP expression between left and right side (Side, $\mathrm{F}_{1,13}=67.40$, $p<0.0001)$. Indeed, all groups that were injected with AAV-GFP displayed a similar degree of GFP immunoreactivity in the ipsilateral side compared to the contralateral side (Supplementary Figure 1D, Sidak, all $p<0.01$ ). Triple immunofluorescence for TH, VMAT2 and GFP further confirmed that all the AAV-GFP injected groups were expressing GFP in midbrain dopaminergic neurons (Supplementary Figure $\left.1 \mathrm{E}-\mathrm{G}_{\mathrm{iii}}\right)$.

\section{Strong transgene overexpression results in $\mathrm{TH}$ downregulation in the striatum and midbrain}

After confirming AAV-mediated expression levels, we investigated whether overexpression of $h-\alpha$ Syn was sufficient to induce a change in the nigrostriatal DA system. We performed immunohistochemical labelling on serial sections for the rate-limiting enzyme in dopamine production, $\mathrm{TH}$, as a proxy marker for dopaminergic neurons (Fig. 3A-D) and demonstrate that in rats injected with the AAV-vector alone or in combination, but not with PFFs alone, there was an overt reduction in $\mathrm{TH}$ immunoreactivity in the striatum and midbrain ipsilateral to the injection. Optical density measurements in the striatum confirmed that there was a difference in $\mathrm{TH}$ staining intensity between groups and hemisphere (Fig. 3H, Group*Side, $\mathrm{F}_{3,17}=12.04, p<0.001$ ). All three AAV-h- $\alpha$ Syn injected groups, but not the PFFs group, displayed a reduction in ipsilateral TH staining intensity which was on average by $52.86 \% \pm$ 5.12 (Fig. 3H, Sidak, all $p<0.0001$ ). Surprisingly, we observed similar results when GFP was overexpressed (Fig. 3E-G). Densitometric analysis of the AAV-GFP injected animals revealed a significant reduction by $69.01 \% \pm 9.00$ in TH staining intensity in the ipsilateral side (Fig. 3I, Side $\mathrm{F}_{1,13}=54.10$, $p<0.0001$, Sidak, all $p<0.01$ ).

To quantify the degree of $\mathrm{TH}+$ neuron loss in the midbrain we performed unbiased stereological counting of $\mathrm{TH}$ immunoreactive cells in the midbrain in the ipsi- and contralateral SN (Fig. 3J). There was a significant difference in the number of $\mathrm{TH}$ immunoreactive cells in the SNpc between the groups and the brain side (Fig. 3J; Group*Side, $\left.\mathrm{F}_{6,24}=4.96, p<0.01\right)$. All AAV-h- $\alpha$ Syn injected groups, but not the PFFs group, displayed a difference between the absolute $\mathrm{TH}^{+}$-cell numbers counted between the injected and non-injected side (Sidak, all $p<0.05$ ). In particular, the $\mathrm{TH}^{+}$cell loss in PFFs, $\mathrm{h}-\alpha$ Syn, $\mathrm{h}-\alpha$ Syn/PFFs, and $\mathrm{h}-\alpha \mathrm{Syn}+\mathrm{PFFs}$ groups was 

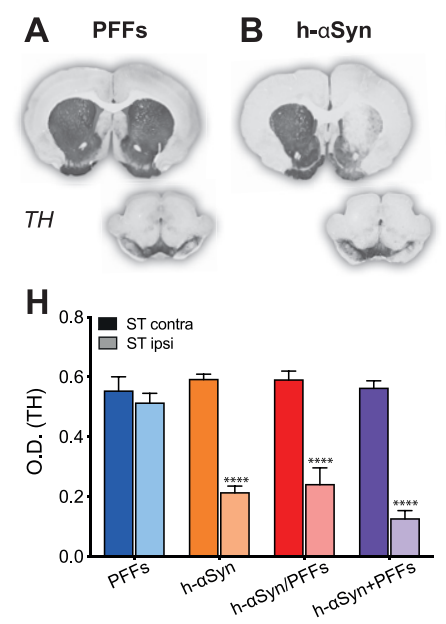
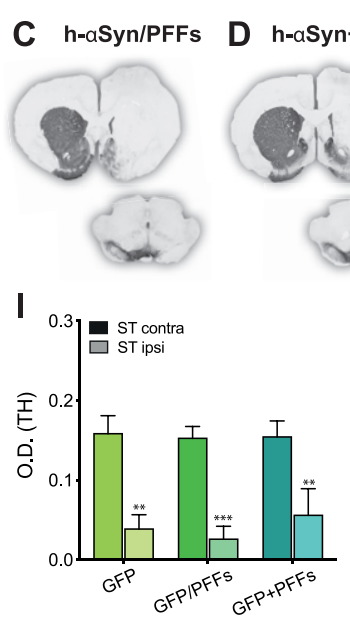
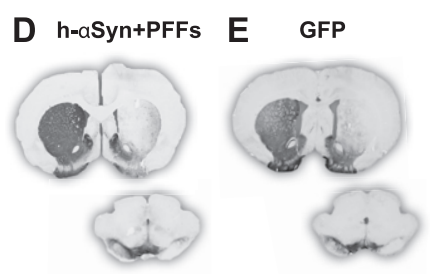

F GFPIPFFs
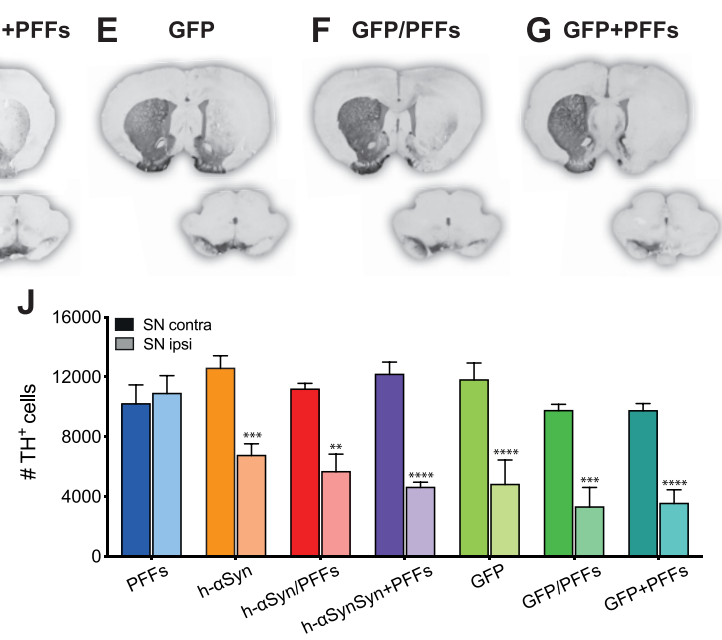

Fig. 3. TH downregulation in striatum and substantia nigra. A-G) TH immunoreactivity from representative midbrain and striatal sections. H-I) Densitometric analysis comparing TH staining intensity between left and right striatum. J) Cell count of $\mathrm{TH}^{+}$cells in the SNpc represented as number of $\mathrm{TH}^{+}$cells between contralateral and ipsilateral SNpc. PFFs, preformed fibrils; h- $\alpha$ Syn, human alpha-synuclein; GFP, green fluorescent protein; ST, striatum; SN, substantia nigra pars compacta; O.D., optical density. Data are expressed as mean \pm SEM. $\left({ }^{* *} p<0.01,{ }^{* * *} p<0.001,{ }^{* * * *} p<0.0001\right)$.

$-3.29 \% \pm 4.44, \quad 31.10 \% \pm 3.29, \quad 34.57 \% \pm 10.91$, and $44.68 \% \pm 4.90$ respectively. Quantification for the AAV-GFP injected groups revealed a reduction in $\mathrm{TH}^{+}$cells in the ipsilateral side similar to that observed for the AAV-h- $\alpha$ Syn injected groups (Sidak, all $p<0.001$ ). Specifically, the $\mathrm{TH}^{+}$cell loss in GFP, GFP/PFFs, and GFP+PFFs groups was $46.38 \% \pm 15.72,52.80 \% \pm 14.12$, and $50.23 \% \pm 11.04$ respectively. Although the $\mathrm{TH}^{+}$loss in the three AAVGFP groups seemed to be higher compared to the loss observed in the three AAV-h- $\alpha$ Syn groups, the comparison between counts in the ipsilateral side did not reach statistical significance (Sidak, all n.s.). Three h$\alpha$ Syn/PFFs rats, one $\mathrm{h}-\mathrm{aSYN}+\mathrm{PFFs}$ rat, one GFP rat, three GFP/PFFs rats, and one GFP+PFFs rat were excluded from the stereological counting due to a coefficient of error (CE) bigger than 0.11 .

Although TH is often used as a proxy marker for cell loss, it does not reveal whether the midbrain dopamine neurons have degenerated or whether there was a mere downregulation of expression as a result of $\alpha$ Syn pathology [27]. To address this question, we performed immunohistochemistry for $\mathrm{TH}$ and NeuN, a pan-neuronal marker. We observed both a loss of TH and NeuN immunoreactive cells ipsilateral to the injection in all groups injected with the AAV-h- $\alpha$ Syn alone or in combination with PFFs, but not in the PFFs-only group (Supplementary Figure $2 A-D_{i i}$ ). A comparison between the AAV-h- $\alpha$ Syn model and the 6-OHDA model showed that the loss of NeuN immunoreactive cells is not restricted to the anatomical location of the SNpc (Supplementary Figure $2 \mathrm{E}-\mathrm{E}_{\mathrm{ii}}$ ). These observations suggest that the $\alpha$ Syn pathology caused a combination of TH downregulation and overt neurodegeneration.

\section{Transgene overexpression results in behavioral impairments with or without additional insult with PFFs}

Assessment of motor function was performed at 4,8 , and 12 weeks after the first surgery. To assess forelimb akinesia and asymmetry we performed stepping and cylinder tests, respectively. Unilateral depletion of dopaminergic signaling was assessed additionally through drug-induced rotation test after $d$-amphetamine injection and eventually through electrochemical detection of striatal DA release.

To facilitate the visualization of the seven groups in the behavioral analyses, graphs for h- $\alpha$ Syn (Fig. 4A, C, E) and GFP control (Fig. 4B, D, F) groups were kept separate; however, statistical analyses were performed with all groups together. Across the three post-injection timepoints, animals in the three AAV-h- $\alpha$ Syn injected groups and AAV-GFP injected groups displayed a bias to neglect the paw contralateral to the side of the lesion, whereas animals in the PFFs-alone group did not display a side bias (Fig. 4A, B). The deficit in the Cylinder test was 

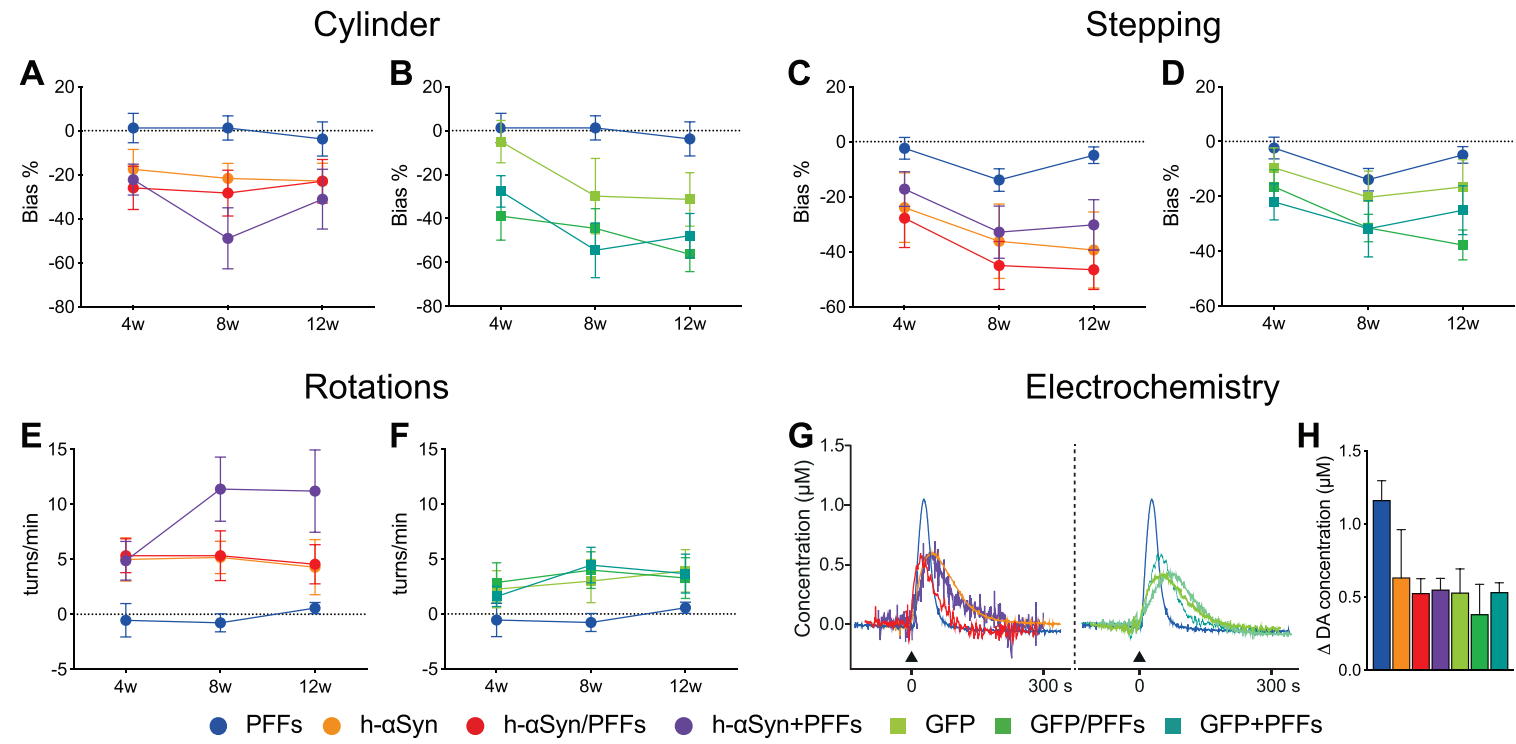

Fig. 4. Behavioral impairments following h- $\alpha$ Syn and/or PFFs injection. A-F) Behavioral tests performed to assess motor function at 4-, 8-, and 12-weeks post-injection for Cylinder, Stepping, and Rotation test for the h- $\alpha$ Syn (circles, A, C, E), GFP (squares, B, D, F), and PFF (circles, A-F) injected groups, respectively. G) Electrochemical recordings (chronoamperometry) for KCl-evoked striatal DA release; black arrow indicates the timepoint of $\mathrm{KCl}$ application. $\mathrm{H}$ ) Average peak amplitude, reflecting the maximum amount of dopamine available, for all the seven experimental groups. PFFs, preformed fibrils; h- $\alpha$ Syn, human alpha-synuclein; GFP, green fluorescent protein; w, weeks; $\mathrm{s}$, seconds. Data are expressed as mean \pm SEM. Note: the behavioral results of the PFFs group are duplicated in each graph for ease of comparison.

slightly more pronounced at week 8 and 12 postinjection (Week, $\mathrm{F}_{2,96}=6.54, p<0.05$ ); however, this effect was not significantly different for the groups (Week ${ }^{*}$ Group, $\mathrm{F}_{12,96}=1.33, p=\mathrm{ns}$ ). Similar to the Cylinder test, animals in the AAV-h- $\alpha$ Syn and AAVGFP injected groups performed fewer adjusting steps on the stepping test compared to their PFFs-only injected counterparts (Fig. 4C, D). Again, there was a significant effect of time (Week, $F_{2,112}=11.08$, $p<0.0001$ ) with performance in week 4 being significantly less pronounced than that in weeks 8 and 12 (Sidak, $p<0.001$ ), indicating a progressive phenotypic evolution of the behavioral deficit on this test. The most commonly used test to assess a unilateral depletion of dopamine is the drug induced rotation test. Here we injected the rats with $2.5 \mathrm{mg} / \mathrm{kg}$ $d$-amphetamine and recorded the rotational behavior for $90 \mathrm{~min}$. As can be seen in Fig. 4E and F, a strong net contralateral rotational response was seen already at the 4 weeks timepoint for all the AAV-h- $\alpha$ Syn injected groups, whereas the PFFs-alone injected group did not display any rotational behavior and the AAV-GFP injected groups had a lower rotational response. Indeed, there was a significant effect of week (Week, $\mathrm{F}_{2,112}=3.19, p<0.05$ ). Over time, all groups maintained a stable behavioral phenotype, except for the $h-\alpha$ Syn + PFFs group which increased its rotational response at 8 and 12 weeks.

One major challenge of the protein overexpression model is the difficulty to establish clear histopathological thresholds for predicting behavioral impairments. Whereas in the classical neurotoxicant-based models (e.g., 6-OHDA) a loss of $70-80 \%$ of dopaminergic neurons is necessary to induce behavioral deficits, in the AAV vector-based models cell loss is not necessary to see behavioral effects. In the toxicant-based models, cell loss is a rather binary event where the cells are either in the process of dying or already degenerated. However, an important aspect of the vector-based models is that neurons can be still alive, albeit severely dysfunctional. To address the neuronal function, we performed electrochemical recordings to investigate the DA release and reuptake kinetics of the remaining dopaminergic fibers in the striatum. As can be seen from the representative traces of individual animals (Fig. 4G) local $\mathrm{KCl}$ application resulted in a reduced peak amplitude in all the groups compared to the PFFs only group. Overall, the peak amplitude, which reflects the maximum amount of DA available, was lower in all the AAV-injected groups compared to the PFFs only group (Fig. 4H). These results are 

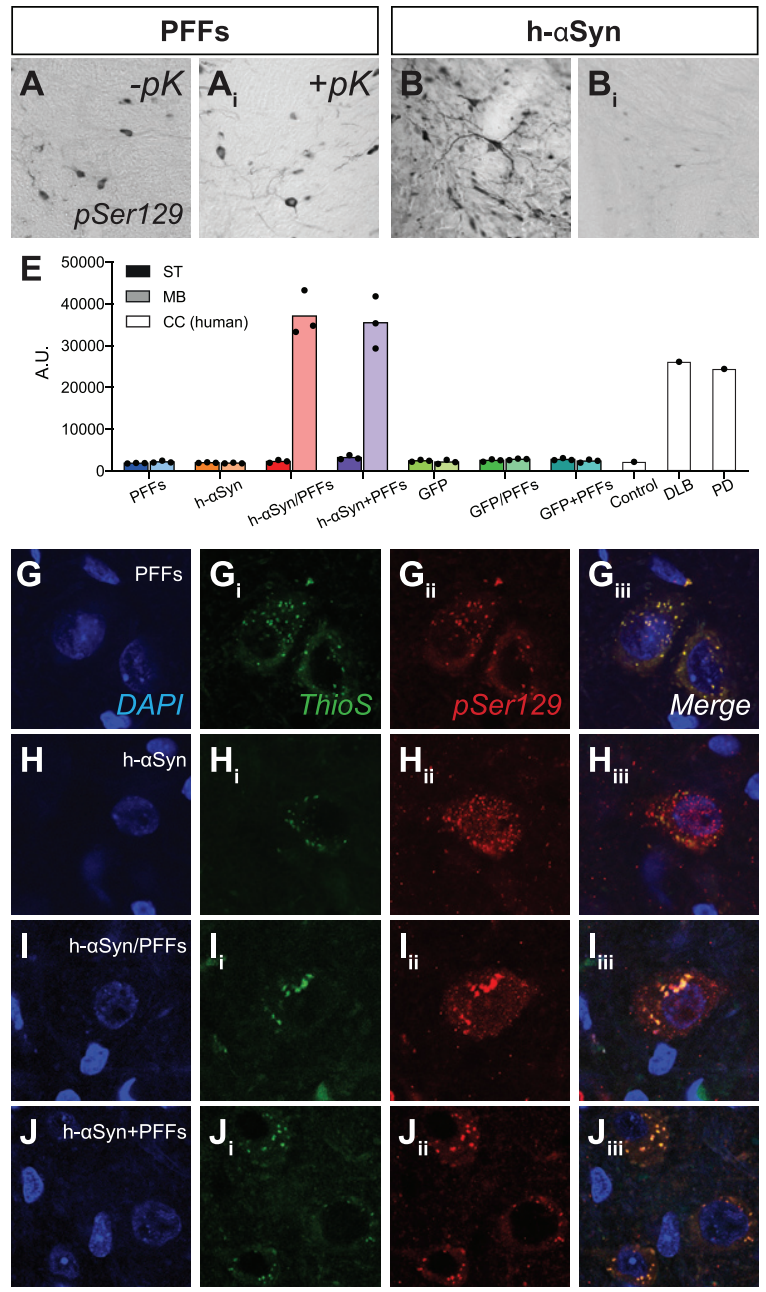
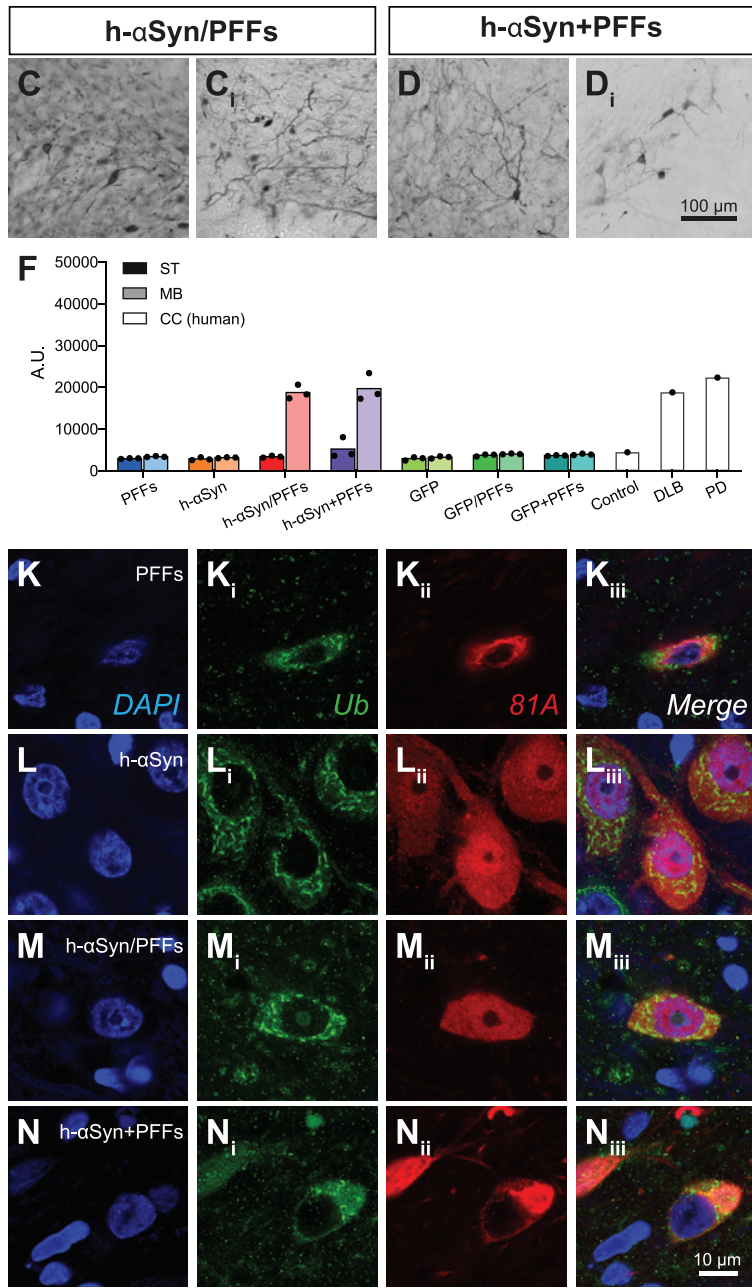

Fig. 5. h- $\alpha$ Syn overexpression and PFFs treatment results in Lewy-like midbrain pathology. A- $\mathrm{D}_{\mathrm{i}}$ ) pSer129 immunoreactivity in midbrain before $(-p K)$ and after $(+p K)$ proteinase K treatment. E, F) TR-FRET quantification of pSer129 (E) and aggregated $\alpha$ Syn $(F)$ in the ipsilateral midbrain and striatum of rats and cingulate cortex of human samples. Black dots represent single subjects. G- $\mathrm{J}_{\text {iii }}$ ) Triple immunofluorescence showing co-localization between pSer129 and Thioflavin S. K-N $\mathrm{N}_{\text {iii }}$ Triple immunofluorescence showing co-localization between 81A (pSer129) and Ubiquitin antibodies. PFFs, preformed fibrils; h- $\alpha$ Syn, human alpha-synuclein; pK, Proteinase K; Ub, ubiquitin; ThioS, Thioflavin S; ST, striatum; MB, midbrain; CC, cingulate cortex. (A.U. = ratio $665 \mathrm{~nm} / 620 \mathrm{~nm}$ multiplied by 10000).

in line with the behavioral deficits and TH downregulation and associated behavioral deficits reported above and suggest that surviving dopaminergic cells are dysfunctional.

\section{h- $\alpha$ Syn overexpression and PFFs inoculation results in parkinsonian-like pathology and inflammatory response}

In human PD, $\alpha$ Syn in Lewy bodies is subjected to post-translational modifications, such as phosphorylation and ubiquitination [59-61]. Moreover, it is known that $\alpha$ Syn fibrils are forming when $\alpha$ Syn assembles in repeated $\beta$-sheet structures, which can be recognized by amyloid-specific dyes such as Thioflavin S [62]. Accordingly, we investigated whether our samples displayed $\alpha$ Syn inclusions with similar histopathological features. pSer129 immunoreactive cells can be detected in the surviving DA neurons in the ipsilateral side in all four target groups (Fig. 5A-D $\mathrm{D}_{\mathrm{i}}$, Supplementary Figure $3 \mathrm{~A}-\mathrm{D}_{\mathrm{ii}}$ ) but not in control groups (Supplementary Figure 3E$\mathrm{G}_{\mathrm{ii}}$. Importantly, the phosphorylated $\alpha \mathrm{Syn}$ inclusions found in all target groups receiving PFFs were resistant to proteinase K-digestion ( $\mathrm{pK}$ ), a feature that is a key characteristic of the Lewy body (Fig. $5 \mathrm{~A}_{\mathrm{i}}, \mathrm{C}_{\mathrm{i}}$, $\mathrm{D}_{\mathrm{i}}$ ). Although there was a substantial amount of punctate pSer129-immunoreactivity in the AAV-h- $\alpha$ Syn 

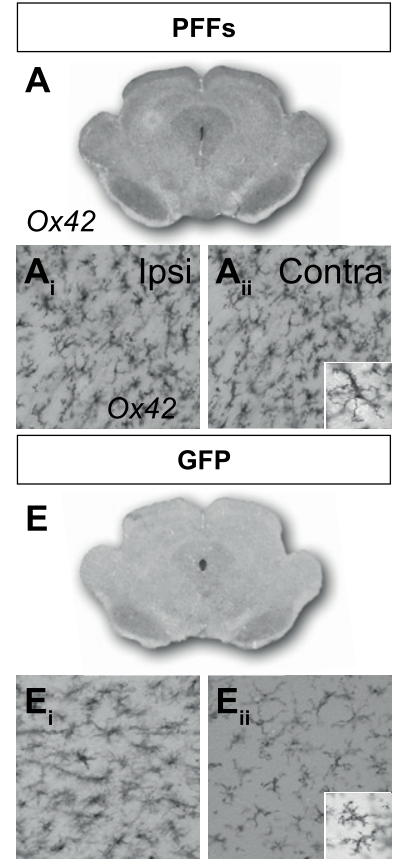
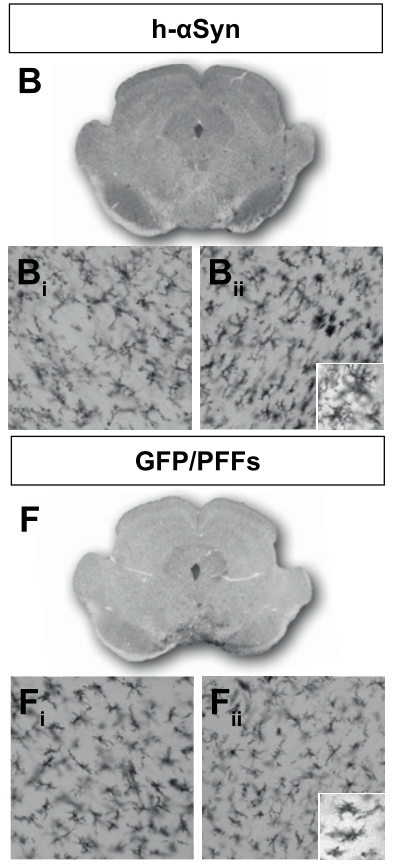
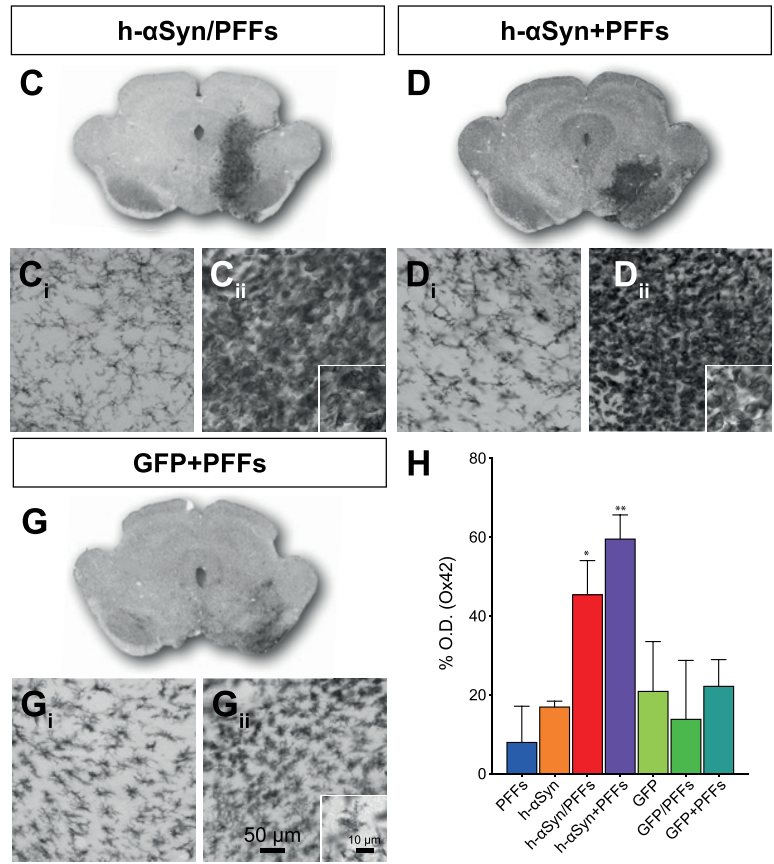

Fig. 6. Inflammatory response. A-G) Overviews of rat midbrain sections stained for Ox42. $A_{i}-G_{i i}$ ) Close-up $20 X$ images for Ox 42 immunoreactivity in contralateral $\left(\mathrm{A}_{\mathrm{i}}-\mathrm{G}_{\mathrm{i}}\right)$ and ipsilateral $\left(\mathrm{A}_{\mathrm{ii}}-\mathrm{G}_{\mathrm{ii}}\right)$ side for target and control groups and additional $63 \mathrm{X}$ magnification images $\left(\mathrm{A}_{\mathrm{ii}}-\mathrm{G}_{\mathrm{ii}}\right)$ for the ipsilateral side. H) Densitometric analysis showing the increase in percentage for Ox42 staining intensity in the ipsilateral midbrain (vs. contralateral) for target and control groups. PFFs, preformed fibrils; h- $\alpha$ Syn, human alpha-synuclein; GFP, green fluorescent protein; Ipsi, ipsilateral; Contra, contralateral. Data are expressed as mean \pm SEM. $\left({ }^{*} p<0.05,{ }^{* *} p<0.01\right)$.

group, after pK-digestion, only little immunoreactivity remained (Fig. $5 \mathrm{~B}_{i}$ ). Quantitatively, h- $\alpha$ Syn/PFFs and $h-\alpha$ Syn + PFFs treated groups showed levels of phosphorylated $\alpha$ Syn (Fig. 5E) and aggregated $\alpha$ Syn (Fig. 5F) in the ipsilateral midbrain comparable to that seen in the brains of human patients with Lewy body dementia or PD. The remaining groups displayed no significant amount of phosphorylated $\alpha$ Syn neither in midbrain nor striatum (data not shown). The lack of $p$ - $\alpha$ Syn or aggregated $\alpha$ Syn in the striatum is not surprising as the timeframe of this study (12 weeks) is likely insufficient for the spread and seeding of pathological $\alpha$ Syn to target areas [37, 63].

Even though detectable levels of aggregated $\alpha$ Syn in midbrain were present only in $h-\alpha \operatorname{Syn} / \mathrm{PFFs}$ and $\mathrm{h}-\alpha$ Syn+PFFs groups, all four target groups showed pSer129+ and Thios ${ }^{+}$inclusions (Fig. 5G-J $\mathrm{J}_{\mathrm{iii}}$ ) and $\mathrm{pSer} / 81 \mathrm{~A}^{+}$and $\mathrm{Ub}^{+}$inclusions (Fig. 5K-N $\mathrm{Nii}_{\text {ii }}$ ), which resemble the histopathological hallmarks presented in human Lewy pathology.

It has been hypothesized that neurodegeneration in PD may result from inflammation in response to abnormal forms of $\alpha \operatorname{Syn}[64,65]$. We therefore investigated whether our samples showed any alteration in the inflammatory response and particularly in microglia activation (Fig. 6A-G). The combination of $h-\alpha$ Syn and PFFs led to a strong microglial activation in the ipsilateral side of the midbrain (Fig. $6 \mathrm{C}_{\mathrm{ii}}$, $\mathrm{D}_{\mathrm{ii}}$ ). When comparing the $\mathrm{Ox} 42$ staining intensity between control side (Fig. $6 A_{i}-G_{i}$ ) and ipsilateral side (Fig. $6 \mathrm{~A}_{\mathrm{ii}}-\mathrm{G}_{\mathrm{ii}}$ ) for the seven groups, using densitometry, we measured a significant increase in the injected hemisphere (Fig. $6 \mathrm{H}$; Side, $\mathrm{F}_{1,33}=22.30, p<0.0001$ ). When compared to the PFFs only group, this increase was only significant for the $\mathrm{h}-\alpha \mathrm{Syn} / \mathrm{PFF}$ and $\mathrm{h}$ $\alpha$ Syn + PFFs groups (Sidak, $p<0.05$ and $p<0.01$, respectively). Microglia of an amoeboid and bushy morphology, indicating a high level of activation compared to the ramified natural state, were present in high amount in animals that received both AAV$h-\alpha$ Syn and PFFs, irrespective whether they were administered simultaneously or sequential (Fig. $6 \mathrm{C}_{\mathrm{ii}}$, $\mathrm{D}_{\mathrm{ii}}$, insets). This pronounced microglial activation was not detected in the control animals (Fig. $6 \mathrm{E}_{\mathrm{ii}}$ $\mathrm{G}_{\mathrm{ii}}$ and $\mathrm{H}$, Sidak, $p=$ n.s.). Co-labelling of $\mathrm{Ox} 42$ and pSer129 (Supplementary Figure 4) showed a strong overlap between the inflammation marker and the marker for phosphorylated $\alpha$ Syn. 

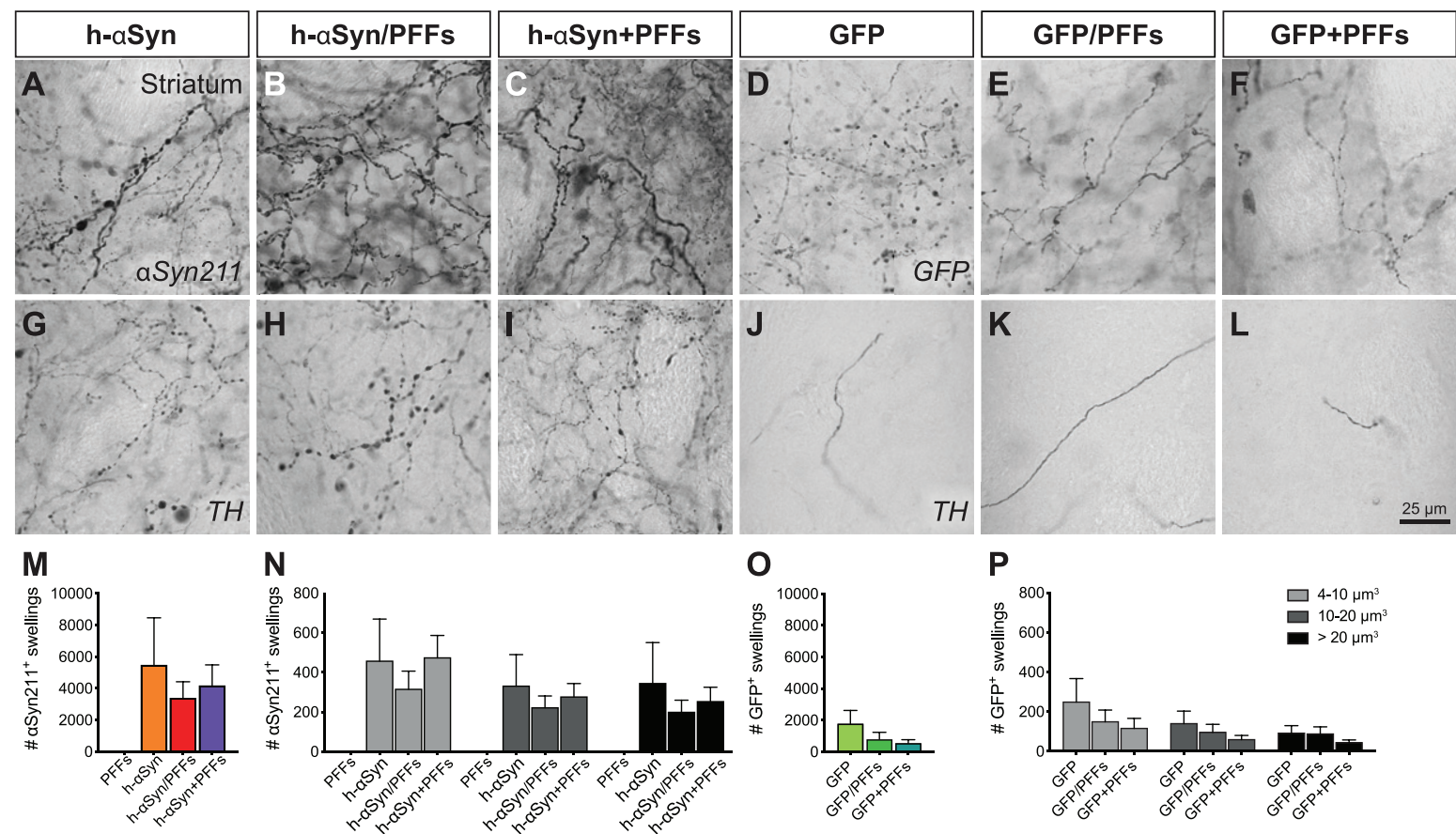

L

$\mathbf{P}$



Fig. 7. Axonal pathology in the ipsilateral striatum. Immunohistochemical analysis to investigate the presence of axonal pathology using antibodies for $\alpha \operatorname{Syn} 211$ (A-C), GFP (D-F), and TH (G-L). Quantification of $\alpha$ Syn211 ${ }^{+}(\mathrm{M}, \mathrm{N})$ and GFP ${ }^{+}$swellings $(\mathrm{O}, \mathrm{P})$ in the ipsilateral striatum. The quantified swellings were counted by total number $(\mathrm{M}, \mathrm{O})$ and volume size $(\mathrm{N}, \mathrm{P})$. PFFs, preformed fibrils; h- $\alpha$ Syn, human alpha-synuclein; GFP, green fluorescent protein. Data are expressed as mean $\pm \mathrm{SEM}$.

\section{Axonal pathology is more pronounced in $A A V-h-\alpha$ Syn injected groups}

The AAV injections caused a distinct dendritic pathology in the terminal fibers of midbrain dopamine neurons. In accordance with the behavioral and electrochemical data, pathological changes in striatal fibers are only seen in groups which received injections of AAV with or without additional PFFs, but not in the PFFs-only group. In high-magnification images of $\alpha$ Syn 211 (Fig. 7A-C) and GFP (Fig. 7D-F) immunoreactivity, swellings can be detected in the three AAV groups, which are absent in the contralateral side of the brain or in PFFs-only rats (Supplementary Figure 5A-C). These swellings appear in single fibers and have a beaded chain-like structure as described previously [19]. In AAV-h- $\alpha$ Syn injected animals, this axonopathy could also be detected after immunohistochemistry for TH (Fig. 7G-I), while it was not detected for the AAV-GFP injected animals (Fig. 7J-L). Again, the contralateral side of the brain and PFFs only group (Supplementary Figure 5D-F) did not display any clear axonopathy.
Volumetric quantification of axonal $\alpha \operatorname{Syn} 211^{+}$, $\mathrm{GFP}^{+}$, and $\mathrm{TH}^{+}$swellings further corroborated these observations. At first, we quantified the number of $\alpha$ Syn $211^{+}$and $\mathrm{GFP}^{+}$swellings in target and control groups, respectively. Overall, AAV-h- $\alpha$ Syn injected groups had higher numbers of swellings than the AAV-GFP injected groups (Fig. 7M, O). The h- $\alpha$ Syn groups had $4465 \pm 1030 \alpha$ Syn $211^{+}$swellings per brain area analyzed, while GFP control groups had $969 \pm 306 \mathrm{GFP}^{+}$swellings. As expected, PFFs only group did not show relevant numbers of $\alpha \operatorname{Syn} 211^{+}$ swellings $(2 \pm 2)$. We then divided the swellings in small $\left(5-10 \mu \mathrm{m}^{3}\right)$, medium $\left(10-20 \mu \mathrm{m}^{3}\right)$, and large $\left(>20 \mu \mathrm{m}^{3}\right)$ volumes. Overall, the AAV-h- $\alpha$ Syn injected groups had higher number of swellings, independently from the size, than the AAV-GFP injected groups (Fig. 7N, P). Interestingly there was no difference in the quantity of small, medium, and large swellings within groups. Subsequently, we quantified $\mathrm{TH}^{+}$swellings and obtained a proportionally similar outcome as in the previous quantification. Overall, AAV-h- $\alpha$ Syn injected groups had higher number of swellings than the AAV-GFP injected groups (Supplementary Figure 5G, I). Target groups had 
$808 \pm 206 \mathrm{TH}^{+}$swellings per brain area analysed, while control groups had $209 \pm 124 \mathrm{TH}^{+}$swellings. As above, AAV-h- $\alpha$ Syn injected groups had higher number of $\mathrm{TH}^{+}$swellings, independently from the size, than the AAV-GFP injected groups (Supplementary Figure 5H, L) with no clear difference in the quantity of small, medium, and large swellings within groups.

These findings clearly corroborate the observed functional impairments and are indicative of a stage where the dopaminergic cells might be still alive, but dysfunctional. As can be seen in the representative images in Fig. 7, and the volumetric quantifications and the striatal fiber density measures reported previously, the difference in the quantity of $h$ $\alpha$ Syn211/GFP positive fibers and TH positive fibers suggest a downregulation of $\mathrm{TH}$ in the striatum.

\section{DISCUSSION}

In this manuscript we present a direct comparison of AAV-mediated $h-\alpha$ Syn overexpression and inoculation with PFFs either in combination or alone, simultaneous or sequential. In doing so we utilized human protein in a rodent background in order to generate a preclinical rodent model of PD.

\section{$A A V$-vector based overexpression of $h-\alpha S y n$}

AAV vectors are a preferred tool for protein overexpression in vivo providing spatiotemporal control, and they are widely used to generate preclinical models for PD. AAV-based strategies have gone through several generations of development, using a variety of serotypes, promoters, transgenes, and post-transcriptional elements. Additionally, differences between studies in terms of genome copies (gc) injected, volumes and coordinates have introduced a large variability in AAV-h- $\alpha$ Syn mediated histopathological and phenotypical outcomes [11, 12, 66]. Overall, the overexpression of $h-\alpha$ Syn by AAV vectors injected into the midbrain of rodents can lead to a loss of TH expressing midbrain dopamine cells and dopaminergic denervation of the striatum $[18,19,23,36,50,67-70]$. Few studies have confirmed that loss of TH immunoreactivity represents overt neurodegeneration and not simply a loss of TH expression $[19,67,68,70]$. As the levels of degeneration depend on the levels of overexpressed $\alpha$ Syn, there is a need for a vector expression system that achieves robust expression and subsequent degeneration in the majority of test subjects [19, 27]. In our current study, we injected $2.4 \times 10^{10}$ gc of AAV9 car- rying the CBA-h- $\alpha$ Syn construct and animals were tested over a time period of 12 weeks. We observed a stable behavioral deficit, loss of TH immunoreactivity in midbrain and striatum, neuronal cell loss in the midbrain, impaired DA release and reuptake kinetics, as well as relevant pathology such as $\mathrm{TH}^{+}$and $\alpha$ Syn $211^{+}$axonal swellings. Moreover, we report the development of $\mathrm{pSer} 129^{+}, \mathrm{Ub}^{+}$, and $\mathrm{ThioS}^{+}$inclusions in midbrain indicating Lewy-like pathology.

\section{The combinatorial effect of $h-\alpha$ Syn and PFFs}

In the human condition one of the pathological hallmarks of PD is the formation of Lewy bodies and Lewy neurites in cortical and subcortical structures, with one of the major components being insoluble oligomers of $\mathrm{h}-\alpha$ Syn assemblies [8, 71]. $\alpha$ Syn present in Lewy bodies is post-translationally modified, with phosphorylation at serine 129 and ubiquitination $[59,60]$ being among the predominant modifications. Additionally, $\alpha$ Syn fibrils can be recognized by Thioflavin S dye [62]. Pre-formed fibrils have been used in several model systems such as rats $[37,38,40,42,72]$ and mice $[41,73]$ either alone or in combination with AAV-mediated overexpression of $h-\alpha$ Syn. As PFFs are cleared after injection they are most frequently being injected sequentially after a stable AAV-based overexpression of h- $\alpha$ Syn has been reached for efficient seeding [37]. However, more recent approaches aim for simultaneous injection of AAV and PFFs [40, 42], as this would negate the need for a second surgery.

In the current study, we compare for the first time the simultaneous and sequential strategies. Importantly, we did not observe significant difference between h- $\alpha$ Syn/PFFs and h- $\alpha$ Syn + PFFs groups, indicating that in our experimental setup the timing of PFFs delivery was not relevant in facilitating the development of $\alpha$ Syn pathology. We report pSer129 ${ }^{+}, \mathrm{Ub}^{+}$, and $\mathrm{ThioS}^{+}$inclusions in surviving midbrain neurons in all the groups injected with AAV-h- $\alpha$ Syn and/or PFFs implying the development of Lewy-like pathology. However, this was especially pronounced when AAV-h- $\alpha$ Syn and PFFs were combined, as demonstrated from the TR-FRET quantification of pSer129+ $\alpha$ Syn aggregates in the ipsilateral midbrain. These results can be explained by the fact that we utilized PFFs of human origin in order to better model the aggregation of this species of protein. The efficiency of human PFFs in seeding aggregation of endogenous rat $\alpha \mathrm{Syn}$ is rather scant. Our experimental paradigm thus provides for a backdrop wherein one can study seeding and aggregation 
of the human protein on a rat background. Whereas previous work has largely focused on rodent PFFs which alone can induce $\alpha$ Syn pathology and neurodegeneration in rats [38, 40, 41, 73, 74]. In agreement, our data confirmed that human PFFs alone were insufficient to trigger pathology within 12 weeks, likely due to the inability to recruit of endogenous rat $\alpha$ Syn. Moreover, the seeding ability is highly dependent on the levels of $\alpha$ Syn expressed [75] and it is thus possible that the effects of the PFFs would be more pronounced with longer incubation times in the brain. In contrast, the combination of human $\alpha$ Syn and human PFFs facilitated rapid templating of both endogenous and ectopic $\alpha$ Syn [76], thereby accelerating the pathological timeline of the $\mathrm{AAV}$-vector based overexpression model. One major, albeit valid, critique of AAV vector models is that the levels of $\alpha$ Syn necessary to induce the levels of degeneration leading to behavioral impairments exceed those seen in patients [19]. It is important to keep this limitation in mind and critically evaluate and apply models to the specific research question $[27,77]$. Another interesting difference between the $h-\alpha$ Syn group and the three target groups that were injected with PFFs was the difference in phosphorylated $\alpha$ Syn after enzymatic digestion with $\mathrm{pK}$. The addition of PFFs did produce more Lewy-like insoluble $\alpha$ Syn aggregates whereas the pSer $129^{+}$inclusions were eliminated in the $\mathrm{h}-\alpha$ Syn only group following $\mathrm{pK}$ digestion suggesting that mere $h-\alpha S y n$ overexpression produces a distinct aggregation species from that originating from a PFF seed.

The combination of $h-\alpha$ Syn and PFFs also exerted a pro-inflammatory effect. Microglia are activated by $\mathrm{h}-\alpha$ Syn aggregation and may play a crucial role in PD onset and progression [78]. In pathological conditions, activated microglia migrate to the injury site where they can both exacerbate or relieve disease progression. Our data show that the combination of AAV-h- $\alpha$ Syn and PFFs produced a strong inflammatory response in the side of injection, where microglia had a bushy and amoeboid morphology characteristic of their activated state. This reaction might be due to the high levels of phosphorylated $\alpha$ Syn aggregates present in the midbrain of these animals, as demonstrated by the TR-FRET quantification.

\section{Loss of tyrosine-hydroxylase immunoreactivity and axonal pathology}

The decrease in TH is clearly indicative of changes affecting dopaminergic neurons and several studies have shown that $\alpha$ Syn overexpression can lead to a downregulation of $\mathrm{TH}[27,50,79]$. To address changes in the nigrostriatal DA system we first assessed the difference in $\mathrm{TH}$ immunoreactivity between the injected and the control striatum. Our data shows that $h-\alpha$ Syn overexpression, as well as GFP overexpression, with or without PPFs, induced a strong reduction in striatal TH immunoreactivity. This downregulation was absent only in the PFFs group. This can be indicative of TH downregulation or actual denervation. Corresponding to the striatal densitometry, unbiased stereology of $\mathrm{TH}^{+}$cells in the $\mathrm{SNpc}$ demonstrated a loss of $\mathrm{TH}^{+}$neurons ipsilateral to the injection for all the groups except the PFFs only group. A reduction in TH immunoreactivity does not causally demonstrate neurodegeneration, therefore we used double labelling for TH and the neuronal marker NeuN, confirming that the AAVmediated overexpression does indeed lead to a loss of DA cells in the midbrain. Interestingly, the pattern of neurodegeneration appeared to spread beyond that seen with a typical 6-OHDA lesion which is specific to DA neurons.

It is important to note that the majority of preclinical rodent models of AAV vector based overexpression of $\alpha$ Syn has focused mainly on the loss of dopaminergic neurons alone, but axon loss and dysfunction is an early and predominant feature of PD which has been postulated to exhibit retrograde degeneration (as discussed in [80]). In the present study, AAV-h- $\alpha$ Syn injected animals, but not AAVGFP injected groups, displayed an elevated number of axonal swellings in the dorsolateral striatum, the region which underlie motor function in PD.

\section{Behavioral impairments}

In humans, about $30 \%$ of SNpc dopamine neurons and about $50-70 \%$ of striatal dopaminergic terminals are lost by the time of symptom onset [81-83]. In the present study we observed about $37 \%$ of $\mathrm{TH}$ loss in SNpc and $53 \%$ in striatum of AAV-h- $\alpha$ Syn groups with evident dysmorphic axons, and $49 \%$ of TH loss in SNpc and 69\% in striatum of AAVGFP groups with low axonal dysmorphia. In our study, both treatment paradigms resulted in behavioral deficits, which remained stable over a period of 12 weeks. For the $d$-amphetamine induced rotations, most rats reached the behavioral threshold that is considered to be indicative of a well lesioned rat of five rotations per minute (rpm) at 8 weeks [84-86]. The threshold of $5 \mathrm{rpm}$ as chosen here is considered quite 
conservative as similar studies had either lower "success" rates (e.g., 25\% [11]) or used a more lenient threshold of $3 \mathrm{rpm}$ (e.g., [19]). It is worth also mentioning that the rotational response to $\mathrm{d}$-amphetamine seen in rats is neither a naturally occurring behavior, nor does it have a linear relationship with cell loss $[84,85]$. Therefore, of interest are the non-drug induced behavioral tests, where we report distinct and stable lateralized deficits in paw use on the Cylinder test (20-50\% bias) and on the Stepping test (20-50\% bias) for all the groups except the PFFs only group. Similar deficits have been reported on the Cylinder test when overexpressing the A53T mutant form of $\alpha$ Syn [23]. An interesting aspect of the AAV vector model compared to the classic neurotoxicant-based models is the fact that the behavioral impairments cannot be easily ascribed to TH-cell numbers alone. In the AAV-based model, depending on the level of transgene expression, the neuron can persist in a dysfunctional state. Many presynaptic and axonal transport proteins are indeed downregulated before overt loss of dopaminergic fibers takes place [69] and striatal dopamine levels are significantly reduced as shown by HPLC [87]. As absolute cell counts do not provide an indication of the level of functional impairment, methods such as electrochemistry are valuable additions to the characterization of the model or intervention and warrant further investigation. On the other hand, in the neurotoxicant-based models neuronal death occurs rapidly and resembles an advanced disease stage. In our study the combination of $\mathrm{TH}$ loss, neurodegeneration, and axonal pathology were associated with impairments in DA release- and reuptake kinetics as measured by electrochemical recordings (chronoamperometry) in the striatum. Our results suggest a direct effect of $\alpha$ Syn on the functionality of dopaminergic axons, which is further supported by the impaired dopamine transmission reported by us and others [50, 88, 89].

In conclusion, the pathology observed in our model is more likely caused by a combination of axonal dysfunction, TH downregulation and actual neurodegeneration. In our own work we have compared several AAV-vector constructs and observed variable behavioral and electrochemical outcomes, even though the histopathology appeared similar and in agreement with previous studies [19, 37, 90]. Importantly, we did not observe any differences between the simultaneous or sequential addition of PFFs with respect to histopathology and behavioral phenotype.

\section{GFP as a control protein in AAV overexpression} studies

GFP is a commonly used control protein in AAV overexpression-based studies. However, it has been reported that GFP can induce in vivo toxicity and can lead to a decrease in TH immunoreactivity [27, $28,30]$. In order to mitigate this unspecific TH loss, some studies have been lowering the titer of the AAV-GFP compared to the AAV-h- $\alpha$ Syn $[11,36$, 91], but this approach might not be ideal in studies where protein overexpression is used to cause cell loss. The levels at which GFP vectors become toxic are not clear, and it is difficult to determine the exact gc titer in which the $\alpha$ Syn construct is inducing pathology while the GFP control vector has no significant effect. Albert et al. (2019) [27] reported that the GFP vector becomes significantly toxic at $3.5 \times 10^{10} \mathrm{gc}$ whereas Landeck et al. (2017) [28] set this threshold above $4 \times 10^{11}$ gc. Differences in the experimental setup, vector construct and titration method do not allow for a direct comparison between studies, and it is therefore not possible to provide a precise estimate. From our own work we report neurotoxicity of $h-\alpha$ Syn and GFP at levels above $2.4 \times 10^{10} \mathrm{gc}$, with minor dissimilarities between the two proteins. Differences between the present work and those reported previously may additionally come from the AAV quantification method utilized. ddPCR-based quantification is less variable than using $\mathrm{qPCR}$, which can produce results varying of a factor of two or even more [92]. Therefore, in such studies where a qPCR-based quantification method was used, the actual titers might have been lower than those reported. In the present study, we injected $2.4 \times 10^{10} \mathrm{gc}$ of an AAV9 carrying the CBA-GFP construct. We observed a stable behavioral deficit, TH downregulation in midbrain and striatum and impaired dopamine release and reuptake kinetics similarly to what observed in AAV-h- $\alpha$ Syn injected animals. However, AAV-GFP injected animals displayed fewer levels of axonal swellings and absence of pSer $129^{+}$inclusions. Our results confirm that exogenous protein overexpression can lead to unspecific neuronal pathology when it exceeds a certain threshold. The use of GFP as control protein should be taken carefully as it can complicate the interpretation of results. Alternatives such as "empty" AAVs, or AVVs carrying an inducible genome or missing the transgene might be used instead of the prototypical GFP control [27, 93, 94]. 


\section{CONCLUSION}

We present here a direct comparison of synucleinopathy models which result in overt dopaminergic degeneration and reliably produce a stable behavioral phenotype. Importantly, the AAV9-CBA construct utilized in our work does allow for studies to be conducted within a reasonable timeframe where neuroprotective and restorative treatments are still a viable option. However, as stated above, the levels of protein expression needed to induce a stable behavioral phenotype makes the choice of an appropriate control vector difficult. In the current study, GFP overexpression was as toxic as $h-\alpha$ Syn overexpression and it therefore complicated the identification of the pathological effects specific to $\alpha$ Syn. The transgene overexpression led to stable behavioral phenotypes, TH loss, and changes in DA kinetics. However, the presence of $h-\alpha$ Syn induced relevant axonal pathology, and the addition of PFFs did generate additional cell body pathology that shares some of the characteristic of human Lewy bodies. Importantly, the simultaneous injection of PFFs led to a comparable model which avoids the confounding effect of repeated injection mechanical injury of the sequential approach. This model can represent a robust platform for the study of PD related $h-\alpha$ Syn etiology and the development of novel targets.

\section{ACKNOWLEDGMENTS}

MD would like to thank the Royal Physiographic Society of Lund (Kungliga Fysiografiska sällskapet), the Royal Swedish Academy of Sciences (Kungliga Vetenskapsakademien) and the Per-Eric och Ulla Schybergs foundation for financial support. FPM was supported by NIH/NIDDK R01DK108798. RM and AF are supported by the EU Joint Programme on Neurodegenerative Disease Research and Agence National de la Recherche (contracts PROTEST-70, ANR-17-JPCD-0005-01 and Trans-PathND, ANR-17-JPCD-0002-02). This work has also received support from the European Union's Horizon 2020 research and innovation programme and EFPIA Innovative Medicines Initiative 2 grant agreements No 116060 (IMPRiND) and No 821522 (PD-MitoQUANT), the Swiss State Secretariat for Education, Research and Innovation (SERI) and Parkinson UK. AH would like to acknowledge generous funding by the Swedish Research Council (VR2016-01789), Demensförbundet, the
Crafoord foundation, the Gyllenstiernska Krapperupsstiftelsen, the Thorsten and Elsa Segerfalks Stiftelsen, the Ake Wibergstiftelsen, the Kockskastiftelsen, the Royal Physiographic Society in Lund, the Swedish Parkinson Foundation (Parkinsonsfonden), the Fredrik och Ingrid Thurings Stiftelsen, the Swedish Society of Medicine (SSMF), the Åhlensstiftelsen, the Hedlundsstiftelsen, the Svenska Läkaresällskapet and the Jeansonsstiftelsen.

\section{CONFLICT OF INTEREST}

The authors have no conflict of interest to report.

\section{SUPPLEMENTARY MATERIAL}

The supplementary material is available in the electronic version of this article: https://dx.doi.org/ 10.3233/JPD-212555.

\section{REFERENCES}

[1] Grealish S, Xie L, Kelly M, Dowd E (2008) Unilateral axonal or terminal injection of 6-hydroxydopamine causes rapid-onset nigrostriatal degeneration and contralateral motor impairments in the rat. Brain Res Bull 77, 312-319.

[2] Kirik D, Rosenblad C, Bjorklund A (1998) Characterization of behavioral and neurodegenerative changes following partial lesions of the nigrostriatal dopamine system induced by intrastriatal 6-hydroxydopamine in the rat. Exp Neurol 152, 259-277.

[3] Heikkila RE, Nicklas WJ, Vyas I, Duvoisin RC (1985) Dopaminergic toxicity of rotenone and the 1-methyl-4phenylpyridinium ion after their stereotaxic administration to rats: Implication for the mechanism of 1-methyl-4phenyl-1,2,3,6-tetrahydropyridine toxicity. Neurosci Lett 62, 389-394.

[4] Sundstrom E, Stromberg I, Tsutsumi T, Olson L, Jonsson G (1987) Studies on the effect of 1-methyl-4-phenyl-1,2,3,6tetrahydropyridine (MPTP) on central catecholamine neurons in C57BL/6 mice. Comparison with three other strains of mice. Brain Res 405, 26-38.

[5] Gerhardt G, Rose G, Stromberg I, Conboy G, Olson L, Jonsson G, Hoffer B (1985) Dopaminergic neurotoxicity of 1-methyl-4-phenyl-1,2,3,6-tetrahydropyridine (MPTP) in the mouse: An in vivo electrochemical study. J Pharmacol Exp Ther 235, 259-265.

[6] Ungerstedt U, Arbuthnott GW (1970) Quantitative recording of rotational behavior in rats after 6-hydroxy-dopamine lesions of the nigrostriatal dopamine system. Brain Res $\mathbf{2 4}$, 485-493.

[7] Tofaris GK, Razzaq A, Ghetti B, Lilley KS, Spillantini MG (2003) Ubiquitination of alpha-synuclein in Lewy bodies is a pathological event not associated with impairment of proteasome function. J Biol Chem 278, 44405-44411.

[8] Spillantini MG, Schmidt ML, Lee VM, Trojanowski JQ, Jakes R, Goedert M (1997) Alpha-synuclein in Lewy bodies. Nature 388, 839-840. 
[9] Braak H, Braak E (2000) Pathoanatomy of Parkinson's disease. J Neurol 247 Suppl 2, II3-10.

[10] Lauwers E, Debyser Z, Van Dorpe J, De Strooper B, Nuttin B, Baekelandt V (2003) Neuropathology and neurodegeneration in rodent brain induced by lentiviral vector-mediated overexpression of alpha-synuclein. Brain Pathol 13, 364-372.

[11] Kirik D, Rosenblad C, Burger C, Lundberg C, Johansen TE, Muzyczka N, Mandel RJ, Bjorklund A (2002) Parkinsonlike neurodegeneration induced by targeted overexpression of alpha-synuclein in the nigrostriatal system. $J$ Neurosci 22, 2780-2791.

[12] Klein RL, King MA, Hamby ME, Meyer EM (2002) Dopaminergic cell loss induced by human A30P alphasynuclein gene transfer to the rat substantia nigra. Hum Gene Ther 13, 605-612.

[13] Lo Bianco C, Schneider BL, Bauer M, Sajadi A, Brice A, Iwatsubo T, Aebischer P (2004) Lentiviral vector delivery of parkin prevents dopaminergic degeneration in an alphasynuclein rat model of Parkinson's disease. Proc Natl Acad Sci U S A 101, 17510-17515.

[14] Yamada M, Iwatsubo T, Mizuno Y, Mochizuki H (2004) Overexpression of alpha-synuclein in rat substantia nigra results in loss of dopaminergic neurons, phosphorylation of alpha-synuclein and activation of caspase-9: Resemblance to pathogenetic changes in Parkinson's disease. $J$ Neurochem 91, 451-461.

[15] Azeredo da Silveira S, Schneider BL, Cifuentes-Diaz C, Sage D, Abbas-Terki T, Iwatsubo T, Unser M, Aebischer P (2009) Phosphorylation does not prompt, nor prevent, the formation of alpha-synuclein toxic species in a rat model of Parkinson's disease. Hum Mol Genet 18, 872-887.

[16] Gorbatyuk OS, Li S, Sullivan LF, Chen W, Kondrikova G, Manfredsson FP, Mandel RJ, Muzyczka N (2008) The phosphorylation state of Ser-129 in human alphasynuclein determines neurodegeneration in a rat model of Parkinson disease. Proc Natl Acad Sci U S A 105, 763-768.

[17] Sanchez-Guajardo V, Febbraro F, Kirik D, Romero-Ramos M (2010) Microglia acquire distinct activation profiles depending on the degree of alpha-synuclein neuropathology in a rAAV based model of Parkinson's disease. PLoS One 5, e8784.

[18] Decressac M, Mattsson B, Bjorklund A (2012) Comparison of the behavioural and histological characteristics of the 6-OHDA and alpha-synuclein rat models of Parkinson's disease. Exp Neurol 235, 306-315.

[19] Decressac M, Mattsson B, Lundblad M, Weikop P, Bjorklund A (2012) Progressive neurodegenerative and behavioural changes induced by AAV-mediated overexpression of alpha-synuclein in midbrain dopamine neurons. Neurobiol Dis 45, 939-953.

[20] Ulusoy A, Decressac M, Kirik D, Bjorklund A (2010) Viral vector-mediated overexpression of alpha-synuclein as a progressive model of Parkinson's disease. Prog Brain Res 184, 89-111.

[21] Aldrin-Kirk P, Davidsson M, Holmqvist S, Li JY, Bjorklund T (2014) Novel AAV-based rat model of forebrain synucleinopathy shows extensive pathologies and progressive loss of cholinergic interneurons. PLoS One 9, e100869.

[22] Kanaan NM, Sellnow RC, Boye SL, Coberly B, Bennett A, Agbandje-McKenna M, Sortwell CE, Hauswirth WW, Boye SE, Manfredsson FP (2017) Rationally engineered AAV capsids improve transduction and volumetric spread in the CNS. Mol Ther Nucleic Acids 8, 184-197.
[23] Van der Perren A, Toelen J, Casteels C, Macchi F, Van Rompuy AS, Sarre S, Casadei N, Nuber S, Himmelreich U, Osorio Garcia MI, Michotte Y, D'Hooge R, Bormans G, Van Laere K, Gijsbers R, Van den Haute C, Debyser Z, Baekelandt V (2015) Longitudinal follow-up and characterization of a robust rat model for Parkinson's disease based on overexpression of alpha-synuclein with adeno-associated viral vectors. Neurobiol Aging 36, 15431558.

[24] Gaugler MN, Genc O, Bobela W, Mohanna S, Ardah MT, El-Agnaf OM, Cantoni M, Bensadoun JC, Schneggenburger R, Knott GW, Aebischer P, Schneider BL (2012) Nigrostriatal overabundance of alpha-synuclein leads to decreased vesicle density and deficits in dopamine release that correlate with reduced motor activity. Acta Neuropathol 123, 653-669.

[25] Landeck N, Strathearn KE, Ysselstein D, Buck K, Dutta S, Banerjee S, Lv Z, Hulleman JD, Hindupur J, Lin LK, Padalkar S, Stanciu LA, Lyubchenko YL, Kirik D, Rochet JC (2020) Two C-terminal sequence variations determine differential neurotoxicity between human and mouse alphasynuclein. Mol Neurodegener 15, 49.

[26] Febbraro F, Sahin G, Farran A, Soares S, Jensen PH, Kirik D, Romero-Ramos M (2013) Ser129D mutant alpha-synuclein induces earlier motor dysfunction while S129A results in distinctive pathology in a rat model of Parkinson's disease. Neurobiol Dis 56, 47-58.

[27] Albert K, Voutilainen MH, Domanskyi A, Piepponen TP, Ahola S, Tuominen RK, Richie C, Harvey BK, Airavaara M (2019) Downregulation of tyrosine hydroxylase phenotype after AAV injection above substantia nigra: Caution in experimental models of Parkinson's disease. J Neurosci Res 97, 346-361.

[28] Landeck N, Buck K, Kirik D (2017) Toxic effects of human and rodent variants of alpha-synuclein in vivo. Eur J Neurosci 45, 536-547.

[29] Koprich JB, Johnston TH, Huot P, Reyes MG, Espinosa M, Brotchie JM (2011) Progressive neurodegeneration or endogenous compensation in an animal model of Parkinson's disease produced by decreasing doses of alphasynuclein. PLoS One 6, e17698.

[30] Klein RL, Dayton RD, Leidenheimer NJ, Jansen K, Golde TE, Zweig RM (2006) Efficient neuronal gene transfer with AAV8 leads to neurotoxic levels of tau or green fluorescent proteins. Mol Ther 13, 517-527.

[31] Whone AL, Boca M, Luz M, Woolley M, Mooney L, Dharia S, Broadfoot J, Cronin D, Schroers C, Barua NU, Longpre L, Barclay CL, Boiko C, Johnson GA, Fibiger HC, Harrison R, Lewis O, Pritchard G, Howell M, Irving C, Johnson D, Kinch S, Marshall C, Lawrence AD, Blinder S, Sossi V, Stoessl AJ, Skinner P, Mohr E, Gill SS (2019) Extended treatment with glial cell line-derived neurotrophic factor in Parkinson's disease. J Parkinsons Dis 9, 301-313.

[32] Whone A, Luz M, Boca M, Woolley M, Mooney L, Dharia S, Broadfoot J, Cronin D, Schroers C, Barua NU, Longpre L, Barclay CL, Boiko C, Johnson GA, Fibiger HC, Harrison R, Lewis O, Pritchard G, Howell M, Irving C, Johnson D, Kinch S, Marshall C, Lawrence AD, Blinder S, Sossi V, Stoessl AJ, Skinner P, Mohr E, Gill SS (2019) Randomized trial of intermittent intraputamenal glial cell line-derived neurotrophic factor in Parkinson's disease. Brain 142, 512-525.

[33] Hoffer BJ, Hoffman A, Bowenkamp K, Huettl P, Hudson J, Martin D, Lin LF, Gerhardt GA (1994) Glial cell linederived neurotrophic factor reverses toxin-induced injury 
to midbrain dopaminergic neurons in vivo. Neurosci Lett 182, 107-111.

[34] Wang Y, Tien LT, Lapchak PA, Hoffer BJ (1996) GDNF triggers fiber outgrowth of fetal ventral mesencephalic grafts from nigra to striatum in 6-OHDA-lesioned rats. Cell Tissue Res 286, 225-233.

[35] Choi-Lundberg DL, Lin Q, Chang YN, Chiang YL, Hay CM, Mohajeri H, Davidson BL, Bohn MC (1997) Dopaminergic neurons protected from degeneration by GDNF gene therapy. Science 275, 838-841.

[36] Decressac M, Ulusoy A, Mattsson B, Georgievska B, Romero-Ramos M, Kirik D, Bjorklund A (2011) GDNF fails to exert neuroprotection in a rat alpha-synuclein model of Parkinson's disease. Brain 134, 2302-2311.

[37] Thakur P, Breger LS, Lundblad M, Wan OW, Mattsson B, Luk KC, Lee VMY, Trojanowski JQ, Bjorklund A (2017) Modeling Parkinson's disease pathology by combination of fibril seeds and alpha-synuclein overexpression in the rat brain. Proc Natl Acad Sci U S A 114, E8284-E8293.

[38] Paumier KL, Luk KC, Manfredsson FP, Kanaan NM, Lipton JW, Collier TJ, Steece-Collier K, Kemp CJ, Celano S, Schulz E, Sandoval IM, Fleming S, Dirr E, Polinski NK, Trojanowski JQ, Lee VM, Sortwell CE (2015) Intrastriatal injection of pre-formed mouse alpha-synuclein fibrils into rats triggers alpha-synuclein pathology and bilateral nigrostriatal degeneration. Neurobiol Dis 82, 185-199.

[39] Volpicelli-Daley LA, Luk KC, Patel TP, Tanik SA, Riddle DM, Stieber A, Meaney DF, Trojanowski JQ, Lee VM (2011) Exogenous alpha-synuclein fibrils induce Lewy body pathology leading to synaptic dysfunction and neuron death. Neuron 72, 57-71.

[40] Peelaerts W, Bousset L, Van der Perren A, Moskalyuk A, Pulizzi R, Giugliano M, Van den Haute C, Melki R, Baekelandt V (2015) alpha-Synuclein strains cause distinct synucleinopathies after local and systemic administration. Nature 522, 340-344.

[41] Luk KC, Kehm V, Carroll J, Zhang B, O’Brien P, Trojanowski JQ, Lee VM (2012) Pathological alpha-synuclein transmission initiates Parkinson-like neurodegeneration in nontransgenic mice. Science 338, 949-953.

[42] Hoban DB, Shrigley S, Mattsson B, Breger LS, Jarl U, Cardoso T, Nelander Wahlestedt J, Luk KC, Bjorklund A, Parmar M (2020) Impact of alpha-synuclein pathology on transplanted hESC-derived dopaminergic neurons in a humanized alpha-synuclein rat model of PD. Proc Natl Acad Sci U S A 117, 15209-15220.

[43] Bousset L, Pieri L, Ruiz-Arlandis G, Gath J, Jensen PH, Habenstein B, Madiona K, Olieric V, Böckmann A, Meier BH, Melki R (2013) Structural and functional characterization of two alpha-synuclein strains. Nat Commun 4, 2575.

[44] Sandoval IM, Kuhn NM, Manfredsson FP (2019) Multimodal production of adeno-associated virus. Methods $\mathrm{Mol}$ Biol 1937, 101-124.

[45] Heuer A, Dunnett SB (2013) Characterisation of spatial neglect induced by unilateral 6-OHDA lesions on a choice reaction time task in rats. Behav Brain Res 237, 215-222.

[46] Ungerstedt U, Butcher LL, Butcher SG, Anden NE, Fuxe K (1969) Direct chemical stimulation of dopaminergic mechanisms in the neostriatum of the rat. Brain Res 14, 461-471.

[47] Olsson M, Nikkhah G, Bentlage C, Bjorklund A (1995) Forelimb akinesia in the rat Parkinson model: Differential effects of dopamine agonists and nigral transplants as assessed by a new stepping test. J Neurosci 15, 38633875.
[48] Schallert T, Norton D, Jones TA (1992) A Clinically relevant unilateral rat model of parkinsonian akinesia. J Neural Transplant Plast 3, 332-333.

[49] Schallert T, Fleming SM, Leasure JL, Tillerson JL, Bland ST (2000) CNS plasticity and assessment of forelimb sensorimotor outcome in unilateral rat models of stroke, cortical ablation, parkinsonism and spinal cord injury. Neuropharmacology 39, 777-787.

[50] Lundblad M, Decressac M, Mattsson B, Bjorklund A (2012) Impaired neurotransmission caused by overexpression of alpha-synuclein in nigral dopamine neurons. Proc Natl Acad Sci U S A 109, 3213-3219.

[51] Hoffman AF, Gerhardt GA (1998) In vivo electrochemical studies of dopamine clearance in the rat substantia nigra: Effects of locally applied uptake inhibitors and unilateral 6-hydroxydopamine lesions. J Neurochem 70, 179-189.

[52] Aldrin-Kirk P, Heuer A, Wang G, Mattsson B, Lundblad M, Parmar M, Bjorklund T (2016) DREADD modulation of transplanted DA neurons reveals a novel parkinsonian dyskinesia mechanism mediated by the serotonin 5-HT6 receptor. Neuron 90, 955-968.

[53] Heuer A, Lelos MJ, Kelly CM, Torres EM, Dunnett SB (2013) Dopamine-rich grafts alleviate deficits in contralateral response space induced by extensive dopamine depletion in rats. Exp Neurol 247, 485-495.

[54] Cresto N, Gardier C, Gaillard MC, Gubinelli F, Roost P, Molina D, Josephine C, Dufour N, Auregan G, Guillermier M, Bernier S, Jan C, Gipchtein P, Hantraye P, ChartierHarlin MC, Bonvento G, Van Camp N, Taymans JM, Cambon K, Liot G, Bemelmans AP, Brouillet E (2021) The C-terminal domain of LRRK2 with the G2019S substitution increases mutant A53T alpha-synuclein toxicity in dopaminergic neurons in vivo. Int J Mol Sci 22, 6760.

[55] Fenyi A, Coens A, Bellande T, Melki R, Bousset L (2018) Assessment of the efficacy of different procedures that remove and disassemble alpha-synuclein, tau and A-beta fibrils from laboratory material and surfaces. Sci Rep $\mathbf{8}$, 10788.

[56] Degorce F, Card A, Soh S, Trinquet E, Knapik GP, Xie B (2009) HTRF: A technology tailored for drug discovery - a review of theoretical aspects and recent applications. Curr Chem Genomics 3, 22-32.

[57] Ip CW, Cheong D, Volkmann J (2017) Stereological estimation of dopaminergic neuron number in the mouse substantia nigra using the optical fractionator and standard microscopy equipment. J Vis Exp, 56103.

[58] Pieri L, Madiona K, Melki R (2016) Structural and functional properties of prefibrillar alpha-synuclein oligomers. Sci Rep 6, 24526.

[59] Fujiwara H, Hasegawa M, Dohmae N, Kawashima A, Masliah E, Goldberg MS, Shen J, Takio K, Iwatsubo T (2002) alpha-Synuclein is phosphorylated in synucleinopathy lesions. Nat Cell Biol 4, 160-164.

[60] Hasegawa M, Fujiwara H, Nonaka T, Wakabayashi K, Takahashi H, Lee VM, Trojanowski JQ, Mann D, Iwatsubo T (2002) Phosphorylated alpha-synuclein is ubiquitinated in alpha-synucleinopathy lesions. J Biol Chem 277, 4907149076.

[61] Anderson JP, Walker DE, Goldstein JM, de Laat R, Banducci K, Caccavello RJ, Barbour R, Huang J, Kling K, Lee M, Diep L, Keim PS, Shen X, Chataway T, Schlossmacher MG, Seubert P, Schenk D, Sinha S, Gai WP, Chilcote TJ (2006) Phosphorylation of Ser-129 is the dominant pathological modification of alpha-synuclein in familial and sporadic Lewy body disease. J Biol Chem 281, 29739-29752. 
[62] Huang Y, Halliday G (2013) Can we clinically diagnose dementia with Lewy bodies yet? Transl Neurodegener $\mathbf{2}, 4$.

[63] Abdelmotilib H, Maltbie T, Delic V, Liu Z, Hu X, Fraser KB, Moehle MS, Stoyka L, Anabtawi N, Krendelchtchikova V, Volpicelli-Daley LA, West A (2017) alpha-Synuclein fibril-induced inclusion spread in rats and mice correlates with dopaminergic Neurodegeneration. Neurobiol Dis 105, 84-98.

[64] Beraud D, Hathaway HA, Trecki J, Chasovskikh S, Johnson DA, Johnson JA, Federoff HJ, Shimoji M, Mhyre TR, Maguire-Zeiss KA (2013) Microglial activation and antioxidant responses induced by the Parkinson's disease protein alpha-synuclein. J Neuroimmune Pharmacol 8, 94-117.

[65] Codolo G, Plotegher N, Pozzobon T, Brucale M, Tessari I, Bubacco L, de Bernard M (2013) Triggering of inflammasome by aggregated alpha-synuclein, an inflammatory response in synucleinopathies. PLoS One $\mathbf{8}$, e55375.

[66] Lo Bianco C, Ridet JL, Schneider BL, Deglon N, Aebischer P (2002) alpha -Synucleinopathy and selective dopaminergic neuron loss in a rat lentiviral-based model of Parkinson's disease. Proc Natl Acad Sci U S A 99, 10813-10818.

[67] Koprich JB, Johnston TH, Reyes MG, Sun X, Brotchie JM (2010) Expression of human A53T alpha-synuclein in the rat substantia nigra using a novel AAV1/2 vector produces a rapidly evolving pathology with protein aggregation, dystrophic neurite architecture and nigrostriatal degeneration with potential to model the pathology of Parkinson's disease. Mol Neurodegener 5, 43.

[68] Oliveras-Salva M, Van der Perren A, Casadei N, Stroobants S, Nuber S, D'Hooge R, Van den Haute C, Baekelandt V (2013) rAAV2/7 vector-mediated overexpression of alpha-synuclein in mouse substantia nigra induces protein aggregation and progressive dose-dependent neurodegeneration. Mol Neurodegener 8, 44.

[69] Chung CY, Koprich JB, Siddiqi H, Isacson O (2009) Dynamic changes in presynaptic and axonal transport proteins combined with striatal neuroinflammation precede dopaminergic neuronal loss in a rat model of AAV alphasynucleinopathy. J Neurosci 29, 3365-3373.

[70] Gombash SE, Manfredsson FP, Kemp CJ, Kuhn NC, Fleming SM, Egan AE, Grant LM, Ciucci MR, MacKeigan JP, Sortwell CE (2013) Morphological and behavioral impact of AAV2/5-mediated overexpression of human wildtype alpha-synuclein in the rat nigrostriatal system. PLoS One 8, e81426.

[71] Fares MB, Jagannath S, Lashuel HA (2021) Reverse engineering Lewy bodies: How far have we come and how far can we go? Nat Rev Neurosci 22, 111-131.

[72] Espa E, Clemensson EKH, Luk KC, Heuer A, Bjorklund T, Cenci MA (2019) Seeding of protein aggregation causes cognitive impairment in rat model of cortical synucleinopathy. Mov Disord 34, 1699-1710.

[73] Masuda-Suzukake M, Nonaka T, Hosokawa M, Oikawa T, Arai T, Akiyama H, Mann DM, Hasegawa M (2013) Prionlike spreading of pathological alpha-synuclein in brain. Brain 136, 1128-1138.

[74] Luk KC, Covell DJ, Kehm VM, Zhang B, Song IY, Byrne MD, Pitkin RM, Decker SC, Trojanowski JQ, Lee VM (2016) Molecular and biological compatibility with host alpha-synuclein influences fibril pathogenicity. Cell Rep 16, 3373-3387.

[75] Courte J, Bousset L, Boxberg YV, Villard C, Melki R, Peyrin JM (2020) The expression level of alpha-synuclein in different neuronal populations is the primary determinant of its prion-like seeding. Sci Rep 10, 4895.
[76] Giasson BI, Forman MS, Higuchi M, Golbe LI, Graves CL, Kotzbauer PT, Trojanowski JQ, Lee VM (2003) Initiation and synergistic fibrillization of tau and alpha-synuclein. Science 300, 636-640.

[77] Barker RA, Björklund A (2020) Animal models of Parkinson's disease: Are they useful or not? J Parkinsons Dis 10, 1335-1342.

[78] Sanchez-Guajardo V, Tentillier N, Romero-Ramos M (2015) The relation between alpha-synuclein and microglia in Parkinson's disease: Recent developments. Neuroscience 302, 47-58.

[79] Perez RG, Hastings TG (2004) Could a loss of alphasynuclein function put dopaminergic neurons at risk? $J$ Neurochem 89, 1318-1324.

[80] Tagliaferro P, Burke RE (2016) Retrograde axonal degeneration in Parkinson disease. J Parkinsons Dis 6, 1-15.

[81] Ma SY, Roytta M, Rinne JO, Collan Y, Rinne UK (1997) Correlation between neuromorphometry in the substantia nigra and clinical features in Parkinson's disease using disector counts. J Neurol Sci 151, 83-87.

[82] Greffard S, Verny M, Bonnet AM, Beinis JY, Gallinari C, Meaume S, Piette F, Hauw JJ, Duyckaerts C (2006) Motor score of the Unified Parkinson Disease Rating Scale as a good predictor of Lewy body-associated neuronal loss in the substantia nigra. Arch Neurol 63, 584-588.

[83] Fearnley JM, Lees AJ (1991) Ageing and Parkinson's disease: Substantia nigra regional selectivity. Brain 114 (Pt 5), 2283-2301.

[84] Bjorklund A, Dunnett SB (2019) The amphetamine induced rotation test: A re-assessment of its use as a tool to monitor motor impairment and functional recovery in rodent models of Parkinson's disease. J Parkinsons Dis 9, 17-29.

[85] Torres EM, Dunnett SB (2007) Amphetamine induced rotation in the assessment of lesions and grafts in the unilateral rat model of Parkinson's disease. Eur Neuropsychopharmacol 17, 206-214.

[86] Torres EM, Lane EL, Heuer A, Smith GA, Murphy E, Dunnett SB (2011) Increased efficacy of the 6-hydroxydopamine lesion of the median forebrain bundle in small rats, by modification of the stereotaxic coordinates. J Neurosci Methods 200, 29-35.

[87] Kim S, Kwon SH, Kam TI, Panicker N, Karuppagounder SS Lee S, Lee JH, Kim WR, Kook M, Foss CA, Shen C, Lee H, Kulkarni S, Pasricha PJ, Lee G, Pomper MG, Dawson VL, Dawson TM, Ko HS (2019) Transneuronal propagation of pathologic alpha-synuclein from the gut to the brain models Parkinson's disease. Neuron 103, 627-641 e627.

[88] Hansen C, Bjorklund T, Petit GH, Lundblad M, Murmu RP, Brundin P, Li JY (2013) A novel alpha-synuclein-GFP mouse model displays progressive motor impairment, olfactory dysfunction and accumulation of alpha-synuclein-GFP. Neurobiol Dis 56, 145-155.

[89] Tozzi A, Sciaccaluga M, Loffredo V, Megaro A, Ledonne A, Cardinale A, Federici M, Bellingacci L, Paciotti S, Ferrari E, La Rocca A, Martini A, Mercuri NB, Gardoni F, Picconi B, Ghiglieri V, De Leonibus E, Calabresi P (2021) Dopaminedependent early synaptic and motor dysfunctions induced by alpha-synuclein in the nigrostriatal circuit. Brain 144, 3477-3491.

[90] Decressac M, Mattsson B, Weikop P, Lundblad M, Jakobsson J, Bjorklund A (2013) TFEB-mediated autophagy rescues midbrain dopamine neurons from alpha-synuclein toxicity. Proc Natl Acad Sci U S A 110, E1817-1826.

[91] Mulcahy P, O'Doherty A, Paucard A, O'Brien T, Kirik D, Dowd E (2012) Development and characterisation of a 
novel rat model of Parkinson's disease induced by sequential intranigral administration of AAV-alpha-synuclein and the pesticide, rotenone. Neuroscience 203, 170-179.

[92] Lock M, Alvira MR, Chen SJ, Wilson JM (2014) Absolute determination of single-stranded and self-complementary adeno-associated viral vector genome titers by droplet digital PCR. Hum Gene Ther Methods 25, 115-125.

[93] Musacchio T, Rebenstorff M, Fluri F, Brotchie JM, Volkmann J, Koprich JB, Ip CW (2017) Subthalamic nucleus deep brain stimulation is neuroprotective in the A53T alphasynuclein Parkinson's disease rat model. Ann Neurol 81, 825-836.
[94] Alarcon-Aris D, Pavia-Collado R, Miquel-Rio L, CoppolaSegovia V, Ferres-Coy A, Ruiz-Bronchal E, Galofre M, Paz V, Campa L, Revilla R, Montefeltro A, Kordower JH, Vila M, Artigas F, Bortolozzi A (2020) Anti-alphasynuclein ASO delivered to monoamine neurons prevents alpha-synuclein accumulation in a Parkinson's disease-like mouse model and in monkeys. EBioMedicine 59, 102944. 